\title{
Sticky information vs. Backward-looking indexation: Inflation inertia in the U.S.
}

Citation for published version (APA):

Carrillo, J. A. (2009). Sticky information vs. Backward-looking indexation: Inflation inertia in the U.S. Algemene Economie 2. METEOR Research Memorandum No. 008 https://doi.org/10.26481/umamet.2009008

Document status and date:

Published: 01/01/2009

DOI:

10.26481/umamet.2009008

Document Version:

Publisher's PDF, also known as Version of record

\section{Please check the document version of this publication:}

- A submitted manuscript is the version of the article upon submission and before peer-review. There can be important differences between the submitted version and the official published version of record.

People interested in the research are advised to contact the author for the final version of the publication, or visit the DOI to the publisher's website.

- The final author version and the galley proof are versions of the publication after peer review.

- The final published version features the final layout of the paper including the volume, issue and page numbers.

Link to publication

\footnotetext{
General rights rights.

- You may freely distribute the URL identifying the publication in the public portal. please follow below link for the End User Agreement:

www.umlib.nl/taverne-license

Take down policy

If you believe that this document breaches copyright please contact us at:

repository@maastrichtuniversity.nl

providing details and we will investigate your claim.
}

Copyright and moral rights for the publications made accessible in the public portal are retained by the authors and/or other copyright owners and it is a condition of accessing publications that users recognise and abide by the legal requirements associated with these

- Users may download and print one copy of any publication from the public portal for the purpose of private study or research.

- You may not further distribute the material or use it for any profit-making activity or commercial gain

If the publication is distributed under the terms of Article $25 \mathrm{fa}$ of the Dutch Copyright Act, indicated by the "Taverne" license above, 


\section{Maastricht University}

Julio A. Carrillo

Sticky information vs. Backwardlooking indexation: I nflation inertia in the U.S.

$\mathrm{RM} / 09 / 008$

\section{METEOR}

Faculty of Economics and Business Administration Maastricht Research School of Economics

of Technology and Organization

P.O. Box 616

NL - 6200 MD Maastricht

The Netherlands 


\title{
Sticky information vs. Backward-looking indexation: Inflation inertia in the U.S.
}

\section{Extended version}

\author{
Julio A. Carrillo* \\ Maastricht University (ALGEC)
}

February 2009

\begin{abstract}
This paper compares two approaches towards the empirical inertia of inflation and output. Two variants that produce persistence are added to a baseline DSGE model of sticky prices: 1) sticky information applied to firms, workers, and households; and 2) a backward-looking inflation indexation along with habit formation. The rival models are then estimated using U.S. data in order to determine their plausibility. It is shown that the sticky information model is better at predicting inflation, wage inflation, and the degree of price stickiness. Output dynamics, however, are better explained by habit persistence.
\end{abstract}

Keywords: Inflation persistence, sticky prices, sticky information

JEL Class.: C12, C13, E31, E52

*Address: Maastricht University (ALGEC), A0.05a, PoBox 616, MD6200 Maastricht, The Netherlands. E-mail: j.carrillo@algec.unimaas.nl. I would like to thank S. Avouyi-Dovi, B. Candelon, M. Dupaigne, P. Falger, P. Fève, J. Matheron, R. Nunes, C. Poilly, R. Wouters, and the participants in the 2008 North American Summer Meeting of the Econometric Society at Carnegie Mellon University, and the 2008 Latin American Meetings of the Econometric Society at Fundaçao Getulio Vargas for their helpful discussions and remarks. All errors are, of course, my own. The author gratefully acknowledges the financial support granted by CONACyT (The National Council for Sciences and Technology of Mexico) during the first stage of the present analysis. 


\section{Introduction}

Inflation inertia and output persistence have become major concerns in monetary economics. Inflation displays not only a sizable inertia, but also a hump-shaped adjustment pattern that lasts for several quarters after a variation in the target interest rate. For the U.S., inflation reaches its peak effect almost 3 years after a shock in monetary policy, while for output this time is about 2 years (see Christiano et al., 1999, 2005). Mojon and Peersman (2003) and Sousa and Zaghini (2004) report that, for Europe, patterns for inflation and output are similar.

Dynamic stochastic general equilibrium (DSGE) models have incorporated two main strategies to explain the observed delayed responses to monetary policy. First, the work of Galí and Gertler (1999) inspired the inclusion of a backward-looking inflation indexation rule for non-resetter firms that has proving to be a powerful tool in replicating the inertia of inflation (see Christiano et al., 2005). Second, environments without full information, such as the sticky information framework popularized by Mankiw and Reis (2002), can also replicate, at least qualitatively, the hump-shaped reaction of inflation.

The aim of this paper is to compare the predictive power of these two alternatives using recent data for the U.S. economy. Attention is focus on the dynamic responses of a set of macroeconomic variables to a shock in monetary policy, the latter estimated with an SVAR with U.S. data for the period 1960(1)-2007(2). The approach employed herein follows the Minimum Distance Estimation (MDE) proposed by Rotemberg and Woodford (1997) and used extensively in papers by Altig et al. (2005), Christiano et al. (2005), Boivin and Giannoni (2006), and others. ${ }^{1}$ In the present analysis, the pur-

\footnotetext{
${ }^{1} \mathrm{MDE}$ is chosen over Bayesian methods in the present analysis because the attention is focus on the medium-run effects of monetary policy on inflation and output. This enables to compare the results of this paper with the previous literature concerning shocks in monetary policy, similar to Christiano et al. (2005) for instance. A Bayesian estimation
} 
pose is to match some selected model-based IRFs with their empirical SVAR counterparts, computed in a previous stage, in order to estimate the parameters that create persistence and hump-shaped patterns in the model economy. Herein, the selected variables are output, inflation, wage inflation, and the target interest rate. This technique has proven to be useful in providing important information about aggregate fluctuations, since the estimation is subject to the model economy cross-equation restrictions and can be set to different response horizons. The latter might provide further information for plausible parameter identification. ${ }^{2}$

The baseline model assumes that prices and wages are rigid. Then, in the first variant, sticky information is added to firms, workers and, households, as proposed by Mankiw and Reis (2007). The second variant is a backwardlooking model, where lagging inflation indexation is assumed for firms and workers, while habit formation is present for households. The backwardlooking model is very similar to that of Christiano et al. (2005).

The main result is that the sticky information model outperforms the backwardlooking model with respect to inflation and wage inflation. Yet, the estimations are very sensitive to the degree of interest rate persistence. As for output, habit persistence proves to be a more powerful tool than applying

would require a more complex model involving different assumptions about the structure of shocks in technology, government spending, cost-push inflation, interest rate spreads, among others. See Smets and Wouters (2007) for an example of a backward-looking DSGE model estimated with Bayesian methods.

${ }^{2}$ Canova and Sala (2007) have raised some identification issues that can be present within the MDE technique applied to IRFs. Their main criticisms are as follows: (1) The objective function may contain large flat surfaces that would avoid a unique parameter identification; (2) Fixing critical parameters may seriously constrain the distribution properties of the estimated parameters; (3) Small sample bias can affect both the identification of shocks in the SVAR and the point estimate of parameters; and (4) Near-observational equivalent models may lead the researcher not to reject an incorrect model specification. All of these points are addressed in the present paper within a robustness analysis. The solutions to these problems are (1) Changing the initial points sufficiently in the estimation algorithm; (2) Performing an extensive sensitivity analysis; (3) Changing the sample period and the response horizons of the estimation; and (4) Simultaneously analyzing two near-observational equivalent models. 
information stickiness in households. Also, the sticky information model estimates a speed of adjustment in prices that is much closer to micro-data studies $^{3}$ than the backward-looking model.

Sticky information can be considered as a potential replacement for lagging inflation indexation in macro models. Though much work needs to be done, this paper provides further evidence to support the sticky information approach extensively studied in the related literature. ${ }^{4}$ This paper is structured as follows. Section 2 contains the sticky information and the backward-looking models used for estimation. Section 3 details the econometric approach. Section 4 discusses the estimation results and performs a robustness analysis. Section 5 offers some concluding remarks. Finally, the Appendix discusses the model details and resolution methods.

\section{Two variants of the sticky price model}

\subsection{Common set-up}

The common economic environment for both models is as follows. A large number of competitive firms produce a homogeneous good using a continuum of differentiated, intermediate goods. The homogeneous good can either be consumed or used in the intermediate sector, where firms employ labor and raw materials as input. Final sector prices are competitive, whereas the intermediate sector is characterized by monopolistic competition. In order to enhance strategic complementarity among price setters, there is an endogenous mark-up that varies with the relative price of the firm and a marginal cost specification that depends on real wages and on the costs of intermediate input. We assume no capital formation; thus, we focus on a model with

\footnotetext{
${ }^{3}$ See Bils and Klenow (2004), and Klenow and Willis (2007).

${ }^{4}$ See, for example, Mankiw and Reis (2002), Dupor et al. (2008), Kiley (2007), Coibion (2007), or Trabandt (2007) for papers that compare sticky information with sticky prices; and Carroll (2003), André, López Salido and Nelson (2005), Khan and Zhu (2006), Korenok (2008) or Mankiw and Reis (2007) for papers that measure the degree of information stickiness in the economy.
} 
short- to medium- run dynamics. Households are composed of two entities: a consumer and a worker. The former chooses consumption, money, and bond holdings, while the latter sets his wage by using his monopolistic power, since every household is different, depending on its labor type. There is no active role for the fiscal authority, while the central bank follows a Taylor rule with policy inertia to set the nominal interest rate. We assume there is only one source of disturbances which correspond to shocks in monetary policy.

Nominal rigidities take the usual Calvo format: in each and every period, an intermediate firm can re-optimize its price with probability $1-\alpha_{p, x}$, while workers can adjust wages with probability $1-\alpha_{w, x}$, with $x \in\{s i, b\}$. The subindex si and $b$ denote the parameters related to the sticky information and the backward-looking models, respectively. If a firm (worker) is unable to re-optimize at period $t$, then, in the sticky information model, its price (wage) is updated in proportion to the steady state inflation; in contrast, in the backward-looking model, a specific indexation rule, that is described later, is used.

It is worth notice that the following models share the same timing restrictions than the SVAR described in Section 3. This is achieved by assuming that output, inflation, and wage inflation are decided prior to the observation of the monetary policy shock, as assumed in Rotemberg and Woodford (1997, 1999) and may others.

\subsection{Sticky information model}

Information flows slowly in this economy. We assume that at each and every period an agent has a probability $1-\gamma_{x, s i}$ of collecting the newest information available; here, $x \in\{p, w, c\}$ denotes firms, workers, or consumers, respectively. As Mankiw and Reis (2007) assume, we allow consumers to have a different frequency of processing new information than workers, since this 
might give more flexibility to output inertia. ${ }^{5}$ The economic environment implies that firms and workers face two rigidity sources. First, they cannot reset prices or wages freely every period, and second, they might not have the newest information about macroeconomic innovations. Since price reoptimizations and information updates are assumed to be processes that are independent of each other, the average elapsed time for price adjustments is $\frac{1}{1-\alpha_{p, s i}}+\frac{1}{1-\gamma_{p, s i}}-1$ periods after a macro innovation takes place (see Bruchez, 2007, for further details). The same reasoning holds for wages. In contrast, average consumers will react only $\frac{1}{1-\gamma_{c, s i}}$ periods after a macro shock. Within this setting, the following relationships must be kept in equilibrium:

$$
\begin{aligned}
\hat{y}_{l, t} & =E_{t-l}\left[\hat{y}_{l, t+1}-\sigma^{-1}\left(\hat{\imath}_{t}-\hat{\Pi}_{t+1}\right)\right] \\
\hat{p}_{l, t} & =E_{t-l}\left[\left(1-\beta \alpha_{p, s i}\right) \tilde{\kappa}_{p}\left(\omega_{p} \hat{Y}_{t}+\hat{W}_{t}\right)+\beta \alpha_{p, s i}\left(\hat{p}_{l, t+1}+\hat{\Pi}_{t+1}\right)\right] \\
\hat{w}_{l, t} & =E_{t-l}\left[\left(1-\beta \alpha_{w, s i}\right) \tilde{\kappa}_{w}\left(\tilde{\omega}_{w} \hat{Y}_{t}-\hat{W}_{t}\right)+\beta \alpha_{w, s i}\left(\hat{w}_{l, t+1}+\hat{\Pi}_{t+1}^{w}\right)\right] \\
\hat{\imath}_{t} & =\rho_{i} \hat{\imath}_{t-1}+\left(1-\rho_{i}\right)\left(a_{\pi} \hat{\Pi}_{t}+a_{y} \hat{Y}_{t}\right)+e_{t} \\
e_{t} & =\rho_{e} e_{t-1}+\sigma_{\nu} \nu_{t} \\
\text { for } \quad l & =1,2,3, \ldots
\end{aligned}
$$

where

$$
\begin{aligned}
\hat{\Pi}_{t}^{w} & =\hat{W}_{t}-\hat{W}_{t-1}+\hat{\Pi}_{t} \\
\hat{Y}_{t} & =\left(1-\gamma_{c, s i}\right) \sum_{l=0}^{\infty} \gamma_{c, s i}^{l} \hat{y}_{l, t} \\
\frac{\alpha_{p, s i}}{1-\alpha_{p, s i}} \hat{\Pi}_{t} & =\left(1-\gamma_{p, s i}\right) \sum_{l=0}^{\infty} \gamma_{p, s i}^{l} \hat{p}_{l, t} \\
\frac{\alpha_{w, s i}}{1-\alpha_{w, s i}} \hat{\Pi}_{t}^{w} & =\left(1-\gamma_{w, s i}\right) \sum_{l=0}^{\infty} \gamma_{w, s i}^{l} \hat{w}_{l, t}
\end{aligned}
$$

and

$$
\tilde{\kappa}_{p} \equiv \frac{1}{\left(1-\mu s_{q}\right)^{-1}\left(1+\theta_{p} \varepsilon_{\mu}\right)+\theta_{p} \omega_{p}} ; \quad \tilde{\kappa}_{\omega} \equiv \frac{1}{1+\omega_{\omega} \theta_{\omega}} ; \quad \tilde{\omega}_{\omega} \equiv \omega_{\omega} \phi+\sigma^{-1}
$$

\footnotetext{
${ }^{5}$ It can also be argued that the probability of a worker's updating information is influenced by the union to which he belongs.
} 
$E_{t-l}$ is the expectations operator conditional to the information available in period $t-l$. Consumption, relative prices, and wages for agents with $l$-lags on their information set are represented by $\hat{y}_{l, t}, \hat{p}_{l, t}$, and $\hat{w}_{l, t}$, respectively. $\hat{W}_{t}$ is the aggregate real wage, $\hat{\Pi}_{t}$ is inflation, $\hat{\Pi}_{t}^{w}$ is wage inflation, $\hat{Y}_{t}$ is aggregate consumption, $\hat{\imath}_{t}$ is the nominal interest rate, and $e_{t}$ represents persistent monetary policy shocks. All variables are expressed as deviations from the steady-state values. $\beta \in(0,1)$ is the subjective discount factor, $\sigma>0$ is the intertemporal elasticity of substitution, $s_{q} \in(0,1)$ represents the share of material goods used by the intermediate sector, $\theta_{p}>0$ is the steady-state price elasticity of demand, $\mu>1$ is the steady-state value of the endogenous mark-up, $\varepsilon_{\mu}$ is the steady-state elasticity of the endogenous mark-up, $\omega_{p}$ is the real marginal cost elasticity with respect to the level of production, $\theta_{\omega}>0$ is the wage elasticity of labor demand, $\omega_{\omega}>0$ is the elasticity of the marginal disutility of labor, and $\phi>1$ is the inverse elasticity of output with respect to labor (see the Appendix section, available in the working paper version, for the detailed presentation of the model).

Equations (1)-(3) are the building blocks of the IS-curve and the Phillipscurves for prices and wages. The monetary policy rule, equation (4), delivers interest rate persistence from two sources. First, the central bank's aim in smoothing the interest rate is denoted by $\rho_{i}$; and second, persistent deviations from the baseline rule, which consists of the discretionary part of monetary policy, are denoted by $\rho_{e}{ }^{6}$

Solving system (1)-(5) requires taking into account the sequence of delayed expectations of endogenous variables, which in this case is infinite. Mankiw and Reis (2007) deal with this problem by employing an undetermined coefficients' solution method. The details of the solution algorithm are depicted in the Appendix.

\footnotetext{
${ }^{6}$ These two sources are both important and have very different implications for the overall macroeconomic sluggishness implied by the model economy (for further details, see Rudebusch, 2006; or Carrillo, Fève and Matheron, 2007).
} 


\subsection{Backward-looking model}

Christiano et al. (2005), among others, consider a version of the new Keynesian sticky price model that incorporates inflation indexation on price and wage setting, and habit formation on consumption. These special features have made it possible to replicate the empirical hump-shaped reactions of inflation and output after a shock in monetary policy. In this model, firms and workers do not face any information lags; thus, prices and wages need on average $\frac{1}{1-\alpha_{x, b}}$ periods to adjust after a macroeconomic innovation (here $x \in\{p, w\})$. Notice that this average duration is structurally different from that on the sticky information model. Furthermore, it is assumed that if a firm (or worker) cannot re-optimize its price (wage) at time $t$, then its price (wage) is updated according to

$$
x_{t}=(1+\pi)^{1-\gamma_{x, b}}\left(1+\Pi_{t-1}\right)^{\gamma_{x, b}} x_{t-1},
$$

where $\pi$ is the steady-state inflation and $0 \leq \gamma_{x, b} \leq 1$ is the degree of indexation to the most recently available inflation measure. When $\gamma_{x, b}=1$, the latter constitutes a special rule with a purely lagging inflation indexation.

Habit formation is introduced by assuming that the weighted difference between actual and past consumption is the relevant consumption argument in the utility function -i.e., $y_{t}-\gamma_{c, b} y_{t-1}$, where $0 \leq \gamma_{c, b}<1$ is the habit persistence parameter. Overall, the aggregate dynamics of the backward-looking model evolve as follows:

$$
\begin{aligned}
\left(1-\beta \gamma_{c, b}\right) \sigma E_{t-1} \hat{\lambda}_{t} & =E_{t-1}\left[\beta \gamma_{c, b} \hat{Y}_{t+1}-\left(1+\beta \gamma_{c, b}^{2}\right) \hat{Y}_{t}+\gamma_{c, b} \hat{Y}_{t-1}\right] \\
\hat{\lambda}_{t} & =E_{t}\left[\hat{\lambda}_{t+1}+\hat{\imath}_{t}-\hat{\Pi}_{t+1}\right] \\
\hat{\Pi}_{t}-\gamma_{p, b} \hat{\Pi}_{t-1} & =E_{t-1}\left[\kappa_{p}\left(\omega_{p} \hat{Y}_{t}+\hat{W}_{t}\right)+\beta\left(\hat{\Pi}_{t+1}-\gamma_{p, b} \hat{\pi}_{t}\right)\right] \\
\hat{\Pi}_{t}^{w}-\gamma_{w, b} \hat{\Pi}_{t-1} & =E_{t-1}\left[\kappa_{w}\left(\omega_{w} \phi \hat{Y}_{t}-\hat{\lambda}_{t}-\hat{W}_{t}\right)+\beta\left(\hat{\Pi}_{t+1}^{w}-\gamma_{w, b} \hat{\Pi}_{t}\right)\right] \\
\hat{\Pi}_{t}^{w} & =\hat{W}_{t}-\hat{W}_{t-1}+\hat{\Pi}_{t}
\end{aligned}
$$

where

$$
\kappa_{p} \equiv \frac{\left(1-\beta \alpha_{p, b}\right)\left(1-\alpha_{p, b}\right)}{\alpha_{p, b}} \tilde{\kappa}_{p} ; \quad \kappa_{\omega} \equiv \frac{\left(1-\beta \alpha_{w, b}\right)\left(1-\alpha_{w, b}\right)}{\alpha_{w, b}} \tilde{\kappa}_{\omega} ;
$$


and $\hat{\lambda}_{t}$ is the marginal utility of income. The monetary policy specification remains unchanged.

\section{Econometric approach}

This section details the monetary SVAR and its implied IRFs that will be used to estimate the two DSGE models described above. It also presents the minimum distance estimation (MDE) approach.

\subsection{The Monetary SVAR and U.S. data}

The analysis starts by characterizing the actual economy's response to a monetary policy shock. As is now standard, this is done by estimating a monetary SVAR along the lines proposed by Christiano, Eichenbaum, and Evans $(1996,1999)$ in order to identify shocks in monetary policy. ${ }^{7}$ We consider a structural SVAR of the form:

$$
A_{0} Z_{t}=A_{1} Z_{t-1}+\cdots+A_{\ell} Z_{t-\ell}+\eta_{t}
$$

In order to identify the structural shocks to monetary policy $\nu_{t}$, a short-run identification strategy using a Cholesky decomposition is employed. Thus, the data vector $Z_{t}$ can be decomposed according to $Z_{t}=\left(Z_{1, t}^{\prime}, \hat{\imath}_{t}, Z_{2, t}^{\prime}\right)^{\prime} . Z_{1, t}$ is a $n_{1} \times 1$ vector composed of variables that do not respond contemporaneously to the monetary shock $\nu_{t}$, and thus are assumed to be predetermined. In contrast, $Z_{2, t}$ is a $n_{2} \times 1$ vector containing variables that are allowed to respond contemporaneously to $\nu_{t}$. The optimal lag length $\ell$ is determined by minimizing the Hannan-Quinn information criterium. In the empirical analysis, $\ell$ is found that be equal to 4 .

The data used for the SVAR come from the U.S. Non-Farm Business sector over the sample period 1960(1)-2007(2). In addition to the federal funds rate,

\footnotetext{
${ }^{7}$ See Christiano et al. (2005); and Rotemberg and Woodford $(1997,1999)$ for other examples of identifying strategies.
} 
$\hat{\imath}_{t}$, the variables used for estimation are the linearly detrended logarithm of per capita GDP, $\hat{Y}_{t}$, the growth rate of GDP's implicit price deflator, $\hat{\Pi}_{t}$, and the growth rate of nominal hourly compensation, $\hat{\Pi}_{t}^{w}{ }^{8}$ In addition, two "information" variables are included. First, the growth rate of the logarithm of the Commodity Research Bureau (CRB) price index of sensitive commodities, $\hat{\Pi}_{t}^{c}$, is considered to mitigate the so-called price puzzle. ${ }^{9}$ Second, the growth rate of $\mathrm{M} 2, \hat{\xi}_{t}$, is included to exploit some potential information involved in money growth. ${ }^{10}$ In order to implement the monetary policy shock's identification strategy outlined above, we set $Z_{1, t}=\left(\hat{Y}_{t}, \hat{\Pi}_{t}, \hat{\Pi}_{t}^{w}, \hat{\Pi}_{t}^{c}\right)^{\prime}$ and $Z_{2, t}=\hat{\xi}_{t}$.

\subsection{Minimum distance estimation strategy}

Let $\psi_{M}$ represent the vector containing all parameters listed in the sticky information model $(M=s i)$ and the backward-looking model $(M=b)$, respectively. Further, let $\psi_{2, M}$ be the vector of parameters to be estimated, while $\psi_{1, M}$ denotes the vector containing all of the remaining parameters, so $\psi_{M}=\left(\psi_{1, M}^{\prime}, \psi_{2_{M}}^{\prime}\right)^{\prime}$. The calibrating parameters $\psi_{1, M}$ will remain fixed through out the estimations and across the models, i.e. $\psi_{1, s i}=\psi_{1, b}=\psi_{1}$. Thus, variations in the empirical performances of the rival models will result only from changes in $\psi_{2, M}$, which refers explicitly to the parameters responsible for creating persistence in each model.

The parameters $\psi_{2, M}$ are estimated by minimizing a measure of the distance between the empirical responses of key aggregate variables and their model

\footnotetext{
${ }^{8}$ The civilian, non-institutional population over 16 was used as a measure of population. Quadratically detrended or first-differenced output were also taken into account as different measures of potential output, without quantitatively altering the main conclusions of the SVAR.

${ }^{9}$ This is a fairly standard practice in the literature. See Sims (1992), Eichenbaum (1992), Christiano et al. (1996, 1999).

${ }^{10}$ The data were extracted from the Bureau of Labor Statistics, the FREDII database, and the CRB.
} 
counterparts. ${ }^{11}$ More precisely, attention is focus on the responses of vector $X_{t}$, which is a subset of $Z_{t}$, and includes output, inflation, wage inflation, and the fed funds rate -i.e., $X_{t}=\left(\hat{Y}_{t}, \hat{\Pi}_{t}, \hat{\Pi}_{t}^{w}, \hat{\imath}_{t}\right)$.

We define $\theta_{k}$ as the vector of responses to a monetary shock at horizon $k \geq 0$, as implied by the above SVAR. Then, the object to match is $\theta=$ $\operatorname{vec}\left(\left[\theta_{0}, \theta_{1}, \ldots, \theta_{K}\right]\right)^{\prime}$, where $K$ is the selected horizon. ${ }^{12}$ We then let $h(\cdot)$ denote the mapping from the structural parameters $\psi_{M}$ to the DSGE counterpart of $\theta$. The estimate of $\psi_{2, M}$ is obtained by minimizing

$$
\mathcal{J}_{T}=\left(h\left(\psi_{M}\right)-\hat{\theta}_{T}\right) V_{T}\left(h\left(\psi_{M}\right)-\hat{\theta}_{T}\right)^{\prime},
$$

where $\hat{\theta}_{T}$ is an estimate of $\theta, T$ is the sample size, and $V_{T}$ is a diagonal matrix with the sample variances of the $\theta$ along the diagonal. These variances are the ones that were used to construct the confidence intervals for the SVAR-based IRFs. In line with Altig et al. (2005), the standard errors for $\psi_{2, M}$ are computed using the delta-function method. The choice of the weighting matrix has some specific advantages. As Christiano et al. (2005) point out, it ensures that the model-based IRFs lie as much as possible inside the SVAR-based IRFs confidence intervals; it also allows one to decompose $\mathcal{J}_{T}$ into components pertaining to each element of $X_{t}$, according to $\mathcal{J}_{T}=\sum_{i=1}^{\operatorname{dim}(X)} \mathcal{J}_{T, i}$. The latter helps us determine on which dimension the model succeeds in or fails to replicate the impulse response functions implied by the SVAR.

\subsection{Calibration and estimating parameters}

Persistence and hump-shaped patterns are the key elements that the rival models need to match. Thus, the estimations focus only on parameters that

\footnotetext{
${ }^{11}$ See Rotemberg and Woodford (1997), Amato and Laubach (2003), Altig et al. (2005), Giannoni and Woodford (2004), Christiano et al. (2005), and Boivin and Giannoni (2006).

${ }^{12}$ It is important to emphasize the DSGE models previously described should include the same time exclusion restrictions as the monetary SVAR, i.e., we should not allow some variables to respond to the monetary policy shock during the impact period.
} 
enable the two DSGE models to mimic this behavior. More specifically, we want to make sure that the models' IRFs depend only on the particular specification of how inertia in inflation, wage inflation, and output are built into each model.

\subsubsection{Set of estimations}

In order to allow a robust investigation, three different sets of estimations are performed. The first, denoted by (1), estimates only the $\gamma$ parameters, that is, the degree of information stickiness in one model, and the degree of backward-looking indexation and habit formation in the other. However, this set does not take into account the different interpretations each model gives to price rigidities. In fact, in the sticky information model, price changes do not translate directly into price adjustments that account for the latest macroeconomic innovations; prices may adjust only to old information. In contrast, the backward-looking model does assume that any price change is, indeed, a price adjustment to the newest macroeconomic innovations.

As a consequence, the average time it takes for prices to reflect changes in monetary policy is structurally different: it is $\frac{1}{1-\gamma_{p, s i}}+\frac{1}{1-\alpha_{p, s i}}-1$ for the sticky information model, while it is $\frac{1}{1-\alpha_{p, b}}$ for the backward-looking model. This suggests that the likelihood of changing prices, $1-\alpha_{p}$, could be very different from one model to the other. This possibility is taken into account in the set of estimations (2), which also includes the $\alpha$ s as estimating parameters.

The set of estimations (3) is a response to the criticism that Canova and Sala (2007) have about the Minimum Distance Estimation technique, namely, that fixing critical parameters may considerably constraint the distribution properties of the estimated parameters. After a round of sensitivity analyses, one finds that these parameters correspond to the persistence in the interest rate. This is not surprising since Rudebusch (2006) and Carrillo et al. (2007) 
show that the source and the degree of interest rate inertia may imply very different aggregate dynamics for inflation and output within a DSGE model. Therefore, at least one of the parameters for the interest rate inertia should be considered for estimation. Carrillo at al. (2007) also show that the interest rate inertia in the U.S. is mainly driven by the discretionary part of monetary policy, in other words, by the parameter $\rho_{e}$ in our setting. Therefore, the parameters estimated in the set (3) are the $\gamma_{\mathrm{s}}$, the $\alpha \mathrm{s}$, and the $\rho_{e}{ }^{13}$

\subsubsection{Calibration}

Calibrating the remaining common parameters can be arbitrary. It is therefore important to make consensual and conservative choices. We must also be sure that the chosen calibration does not imply implausible responses by the models' counterparts of $X_{t}{ }^{14}$ The calibration is reported in Table 1.

Preferences. The subjective discount rate, $\beta$, equals 0.99 , implying a steady-state annualized real interest rate of $4 \%$. We then set $\sigma=\omega_{w}=1$, implying a logarithmic utility for consumption and a unitary elasticity of marginal labor disutility, respectively, as considered by Altig et al. (2005) and Christiano et al. (2005).

Technology. $\phi$, the inverse of the labor input elasticity to output, equals 1.333, denoting decreasing returns to scale in labor. Thus, the steady-state share of labor income is about $62.5 \%$, after correcting for the markup. If the intermediate firm production function is Cobb-Douglas, then $\omega_{p}$ equals $\phi-1$. The share of material goods in gross output, $s_{q}$, is set to $50 \%$, as suggested by Rotemberg and Woodford (1995). Following Rotemberg and Woodford (1997) and Christiano et al. (2005), we set the markup on prices to $20 \%$,

\footnotetext{
${ }^{13}$ Estimations with both interest rate persistence parameters are made in the sensitivity analysis, without changing any of the conclusions of the present paper.

${ }^{14}$ The sensitivity of the results to the calibration is assessed in section 5 .
} 
i.e. $\mu_{p}=1.20$. This implies an elasticity of demand for goods $\theta_{p}=6$. The markup elasticity to relative demand, $\epsilon_{\mu}$, is set to 1 , as used by Woodford (2003). Finally, $\theta_{w}$ is set to 21 as used by Christiano et al. (2005), implying a wage markup of $5 \%$.

Price/Wage Setting. Only to account for the estimation set (1), we set $\alpha_{p}=\alpha_{w}=0.66$, valid for both models. This value is used by Rotemberg and Woodford (1997) and many others, and implies an average time laps for price changes of almost 9 months.

Nominal Interest Rate Target Level. Following Taylor (1993), we set $a_{\pi}=1.5$ and $a_{y}=0.5 / 4$, since we focus on a quarterly measure of the output gap. These values are approximately the same as those considered by Christiano et al. (2005) in their sensitivity analysis. In accordance with the results of Carrillo, Fève and Matheron (2007), $\rho_{i}$ is set to 0.20 , whereas $\rho_{e}$ equals 0.90 , at least for the first two sets of estimations. $\sigma_{\nu}=0.1736$ is set to match the impact response of the fed funds rate to a shock in monetary policy, given by the SVAR.

\section{Empirical results}

\subsection{Responses of U.S. data to a monetary policy shock}

The empirical responses of output, inflation, wage inflation, and interest rate to a contractionary monetary policy shock are reported in Figure 1, with $k=30$. The plain line is the SVAR's point estimate of the empirical responses, while the shaded areas indicate the $90 \%$ confidence interval for the point estimates.

These findings replicate previous results reported by Christiano et al. (1999, 2005), as well as other authors. Output exhibits a significant persistence and a hump-shaped pattern, as it responds very little initially and then sharply 
drops. It reaches its peak two years after the occurrence of the shock in monetary policy. The responses of inflation suggest a small, but insignificant, price-puzzle in the very short run. Nonetheless, inflation reacts with a persistent hump-shaped profile, reaching its peak around three years after the shock. The responses of wage inflation are qualitatively similar, slightly lagging behind inflation. As discussed by Woodford (2003), the delayed response of inflation is a typical behavior that any monetary DSGE model should accurately mimic. Finally, the fed funds rate increases immediately, and then gradually declines to the point where it eventually crosses the $x$ axis.

\subsection{Results of estimations}

Table 2 shows the results of the three sets of estimations proposed in the previous section. One thing we have to keep in mind when analyzing the estimation results is that the models should not describe unrealistic environments, especially with regard to the rate of updating information or the speed of price and wage changes.

Estimation set(1). In this set of estimations, only the degree of information stickiness and the level of backward-looking indexation and habit persistence are estimated. Notably, the frequency of price and wage reoptimizations are kept constant in both models. The values assumed for the $\alpha$ parameters in calibration is set to 0.66 , like many macro models.

In such environment, the sticky information model performs very poorly, as denoted by the large size of the corresponding $\mathcal{J}$-statistic. According to column (1) of Table 2, the sticky information model anticipates that the probability of updating information is 0.29 (=1-0.71) for firms and 0.35 for workers in any period. Thus, any firm or worker would obtain new information on

the average every 9 or 10 months $\left(=\frac{1}{1-\gamma_{x, h}}\right.$ for $x \in\{p, w\}$ in quarters). This implies that prices and wages would reflect adjustments, on the average, one 
year and 4 months after a variation in the interest rate $\left(=\frac{1}{1-\gamma_{j, h}}+\frac{1}{1-\alpha_{j, h}}-1\right.$ in quarters). In the same vein, less than 7 per cent of households obtain new information every quarter, meaning that the average consumer would adjust his spending more than three years after an interest rate change $\left(=\frac{1}{1-\gamma_{c, s i}}\right.$ in quarters). Nevertheless, in all cases, the size of the model responses is too small in comparison with the predictions from the SVAR. In summary, in this setting, the sticky information model fails to reproduce the adequate impulse responses of output and the measures of inflation, as the first row of Figure 1 shows.

In contrast, the results of the backward-looking model are closer to the data and anticipate that firms and workers use full lagging inflation indexation. The parameter for habit persistence, equal to 0.86, lies in the range of available estimates based on aggregate data (see Boivin and Giannoni, 2006; and Christiano et al., 2005). Evidently, the estimation for this model was carried out with the constraint that lagging inflation indexation belongs to the range $[0,1]$, and what we can deduce is that the full power of the backwardlooking model in replicating the data relies on this tool. No more economic explanations can be drawn out from that. The frequency of price and wage changes is fixed after 9 months on the average $\left(=\frac{1}{1-\alpha_{x, b}}\right.$ for $x \in\{p, w\}$ in quarters). One must remember that, in the backward-looking model, price changes translate directly into adjustments to new innovations in the economy. There are, however, inconsistencies when one compares these results with those found in micro-data studies. These issues will be discussed in detail later.

Finally, we see that neither sticky information nor habit persistence seems to successfully predict well the behavior of output after a shock in the interest rate. 
Estimation set (2). Now we let the probability of changing prices and wages be estimated along with the $\gamma$ parameters. In this setting, the results of both models improve substantially, as the $\mathcal{J}$-statistic shows in the bottom of column (2) in Table 2. The backward-looking model still conserves a better goodness-of-fit than sticky information, a result that is mainly achieved by output responses. With regard to inflation and interest rate, the two models do not differ too much from each other. Both inertia and hump-shaped patterns are present in the two models, although the sticky information approach yields less persistence in the measures of inflation.

As anticipated, the sticky information model predicts a rate of changing prices and wages that is substantially less than with the backward-looking model. Nevertheless, the degree of price stickiness and the speed of updating information for firms seem totally unrealistic. According to the estimation of column (2), the sticky information specification anticipates that prices will be fully flexible; the probability of not changing prices of about 6 per cent. In contrast, it predicts that firms seldom learn about new macro innovations, with only 4 per cent updating their information every quarter. Together, the speed of changing prices and the rate of updating information imply that a firm would, on the average, adjust its price more than 6 years after a change in the interest rate $\left(=\frac{1}{1-0.97}+\frac{1}{1-0.025}-1\right.$ in quarters $)$, an unrealistic implication. In contrast, the same analysis for wages presumes it would take 3 years for a worker to adjust to innovations in monetary policy.

The extreme conclusions about the nature of price adjustments in the sticky information model give a clear signal of a substitution effect among the two sources of rigidities in prices. It seems plausible to assume, under such circumstances, that the sticky information model requires very slowly updating of information whenever prices are very flexible, and vice-versa. This issue will be discussed further in the sensitivity analysis. 
With regard to output, the sticky information model still performs very poorly. First, it predicts that the probability of a household updating information every period is less than 5 per cent, which translates into an average duration of consumption adjustment of about 6 years. This finding contrasts greatly with that of Carroll (2003), who, using the Michigan Survey of Consumers, suggests that households update information once a year. Also, Mankiw and Reis (2007), using a maximum likelihood estimation, find that households update their information about every year and a half. Unfortunately, these authors do not assess whether their rates of updating information lead to a proper quantitative reaction to their model-based output with respect to actual output. More work has to be done in this area.

On the other hand, the backward-looking model predicts a somewhat higher degree of price and wage stickiness than what was assumed in estimation set (1). Here, prices would adjust every 11 months on the average, while wages would do so every 14 months. Again, the problem is that these price rigidities are not verified by micro-data studies. When it comes to output, the backward-looking model increases its predictive power when compared to the previous set of estimations.

Estimation set (3). Next, the influence of interest rate inertia is measured by including the parameter $\rho_{e}$ in the estimations. Inclusion of this coefficient is necessary due to the fact that fixing this critical parameter significantly limits the distribution of the estimated coefficients of the sticky information model. ${ }^{15}$ In such a case, we find the following: both models perform better, and they even obtain a similar overall $\mathcal{J}$-statistic. However, a closer look reveals that the composition of the latter differs substantially from model to model. For output, the backward-looking specification is superior to sticky

\footnotetext{
${ }^{15}$ This is a criticism of the MDE estimation technique that has been acknowledged by Canova and Luca (2007) and may explain, in part, the unrealistic point estimates yielded by estimation set (2).
} 
information in explaining the dynamics of consumption and output. The opposite is true for the rest of the variables. Indeed, the goodness-of-fit of sticky information is almost 50 per cent better for the inflation measures and slightly more accurate for the interest rate.

It also worth noting that the point estimates of interest rate inertia are similar in both models to the previous calibrated value of 0.90 . What is surprising is the impact of small changes in this parameter on the models' ability to mimic the behavior of aggregate variables.

In this estimation set, the sticky information model allows less flexibility for prices and wages and a higher speed of information diffusion than estimation set (2). The model anticipates that nearly 11 per cent of firms would update information every period, whereas about 71 per cent might change their prices. For wages, the sticky information model presumes that less than 10 per cent of workers update their information every quarter, while around 67 per cent of them might change their wages.

The backward-looking model yields very consistent estimations about $\alpha_{p}$ with respect to previous estimations. For wages, this model estimates an even higher degree of stickiness. In general, however, we can consider the estimations of the backward-looking model as robust, since there are no big changes in price and wage stickiness, habit formation, or the degree of backwardlooking indexation across the three sets of estimations considered.

Comparison with micro-data studies. The backward-looking model suggests that prices change once a year on the average, and that every price adjustment reflects the newest macroeconomic innovations in the economy. This contrasts shortly with evidence provided at microeconomic levels. Bils and Klenow (2004) report that, in the U.S., using data from the Bureau of 
Labor Statistics and covering 70 per cent of consumer spending, the median duration for price changes is 4.3 months. This confirms the well-known fact that sticky-price models assume much more rigidity than in the real world. Additionally, Klenow and Willis (2007), using micro-data from the U.S. CPI, suggest that price changes react to old information and not to the newest macro innovations.

On the other hand, the sticky information model, as estimated by set (3), tells us that an average firm would re-set its price every 4 months, whereas its information would be updated roughly every two years. Together, these two rigidities would allow the average price to reflect changes in monetary policy after 2 and a half years. This is not only in line with the aforementioned micro evidence, but it is also close to the time at which inflation reaches its peak effect according to the SVAR. This is definitely an advantage compared to standard sticky price models.

For wages, sticky information anticipates that a worker will, on the average, adjust to changes in monetary policy two years and three quarters later. Since the peak effect on wage inflation occurs approximately three years after a monetary policy shock, according to the SVAR estimations, the predictions of this model do not appear unreasonable.

Other estimations for the U.S. Let us compare the present results with those of some other studies concerning the rate of updating information by firms. Dupor et al. (2008) perform estimations for the parameters of the Phillips curve, merging sticky prices and sticky information, just as the sticky information model presented here. Their estimations for price stickiness claim that only 14 per cent $\left(\alpha_{p}=0.86\right)$ of firms change their prices every period and 42 per cent $\left(\gamma_{p}=0.58\right)$ update information. Prices are just too rigid in their estimations, and they are not in line with microeconomic evidence. The high frequency of updating new information in their estimations 
may be due to a substitution effect between price stickiness and information stickiness, as these authors also noticed. We will be return to this issue in the next section.

The speed of updating information has also been estimated in models where only sticky information appears to be the source of rigidity for price setters. Mankiw and Reis (2007) estimated a rate of updating information of 70 per cent in its pure sticky information model. In contrast, Kahn and Zhu (2006) estimate that only 25 per cent of firms would update information every quarter. On the other hand, André, López-Salido and Nelson (2005) suggest that between 15 and 20 per cent of firms update information every period, while Korenok (2008) achieves a point estimate of 0.30 for the same probability.

One drawback of the models that attempt to replace sticky prices with sticky information is that they do not take into account the fact that prices are not fully flexible, as micro data studies show. Prices are, indeed, sticky, but not as much as most macro models suggest. Dupor et al. (2008) also reach the same conclusions. These authors find that aggregate data cannot ignore the significance of price stickiness, despite the presence of slow information spills. Thus, sticky information cannot replace sticky prices; rather than mutually exclusive environments, they seem to be complementary ones. Ignoring price stickiness might bias the estimations about the degree of information stickiness; this could explain the large differences in magnitude reported in the literature.

\section{Sensitivity analysis}

The last section highlighted the importance of selecting certain parameters for estimation in order to improve the goodness-of-fit of both models. Clearly, the probability of changing prices and wages, along with a persistence measure of the interest rate, is crucial for the estimations of both models. In 
this section, we will try to determine whether the results of estimation set (3) are robust to different combinations of calibrated values. In doing so, we will change the value of some key model parameters. Table 3 reports the outcome of this sensitivity analysis. We will identify key parameters governing the dynamic behavior of the models related to preferences, technology, monetary policy rule, and estimation horizon. For each alternative, the specification (3) is re-estimated for each model and the $\mathcal{J}$-statistic is recomputed.

One general observation across the sensitivity analysis is that the sticky information model always performs better in terms of inflation and wage inflation than the backward-looking model, as can be seen when comparing the decomposition of the $\mathcal{J}$-statistic. In contrast, habit formation seems to be a more reliable tool for explaining the dynamics of output than assuming information stickiness in households. This last result seems to be very robust across the estimation of sets (1)-(3) in the last section and again here in the sensitivity analysis.

The ability of both models to replicate the behavior of output, inflation measures, and interest rate does not appear to be heavily affected by modifying the parameters concerning preferences and technology. This is the case when assuming that labor supply becomes highly inelastic $\left(\omega_{w}=10\right)$ or when consumers become highly averse to risk $(\sigma=0.5)$. For technology, if we assume constant returns to scale $(\phi=1)$ there will be a tiny positive impact on the predictions of inflation. Changing the mark-up for the goods market and the labor market also has no significant impact on estimations $\left(\theta_{p}=\theta_{w}=11\right)$. Finally, reinforcing the level of raw material goods in the intermediate sector also seems insignificant $\left(s_{q}=0.7\right)$.

Changing the parameters of the interest rate reaction function has more sizable impacts. When assuming that monetary authorities are very averse to inflation $\left(a_{\pi}=3\right)$, both models see their predictive power diminished to ac- 
tual inflation. In the same vein, if we assume a higher value for the output gap parameter $\left(a_{y}=0.125 * 4\right)$ the models significantly decrease their ability to approximate the behavior of output. As for the sources of interest rate inertia, if we allow $\rho_{i}$ and $\rho_{e}$ to be estimated simultaneously, along with the other parameters considered in estimation set (3), we can see that nothing changes significantly in the $\mathcal{J}$-statistic. Moreover, the estimated values for $\rho_{i}$ and $\rho_{e}$ are close to what was calibrated for the former and estimated for the latter, i.e. 0.34 and 0.92 , respectively, for the sticky information model, while we find 0.25 and 0.92 for the backward-looking model.

When reducing the estimation horizon in terms of the impulse response functions the models have to match, we see that their overall performance is reduced. In any case, the sticky information model is still better at anticipating the dynamics of the inflation measures.

\section{Substitution between price- and information-stickiness in the sticky}

information model. The estimation sets (1)-(3), along with the sensitivity analysis, allow us to see a strong negative relation between the probability of price changes and the rate of updating information. This same observation was made by Dupor et al. (2008). Figure 2 shows the estimated values for the speed in changing prices and updating information that were achieved in the sensitivity analysis, plus the estimation sets (1) - (3). The upper-left panel shows how price stickiness and information stickiness are substitutes in a quite surprisingly regular manner. The same relation for wages is, however, less consistent.

Let us now focus on prices. Among the various combinations of the estimated $(\alpha, \gamma)$ pairs, the ones at the extremes are characterized by high values of the $\mathcal{J}$-statistic, as the bottom left panel of Figure 2 indicates. The pair $(\alpha, \gamma)$ found by Dupor et al., denoted in the figure with a diamond marker, is precisely in one of these extremes. Moreover, if we perform an estimation 
for the sticky information model calibrating $\alpha_{p, s i}$ as Dupor et al.'s value, the point estimate of $\gamma_{p, s i}$ turns out to be 0.43 , somewhat lower than the value they found. The associated $\mathcal{J}$-statistic equals 214.77 , which means that $\mathrm{Du}-$ por et al.'s values have a very poor fit to U.S. data, according to the present methodology. The sticky information model when using their values simply cannot simulate the dynamic behavior of actual inflation. This exercise shows how the use of general equilibrium models may deliver more general conclusions about aggregate fluctuations than the use of single equations.

\section{Concluding remarks}

The present study considers two alternative models to replicate the behavior of output, inflation, wage inflation, and interest rate. Sticky information is added to households, firms, and workers in a model that assumes price stickiness à la Calvo. The second specification concerns backward-looking inflation indexation by firms and workers, plus habit persistence in consumption added also to a sticky price model. Both models are then compared to the estimated aggregate dynamics resulting from a SVAR for the U.S. for the sample period 1960(1)-2007(2).

In general, the backward-looking model delivers robust estimations and predicts that prices will be adjusted once a year. This is, however, considerably more price stickiness than what microeconomic observations suggest. Bils and Klenow (2004) report that the median time for price changes is 4.3 months. The sticky information model is in line with this evidence, since it predicts that an average firm would change its prices every 4 months, whereas its information would be updated roughly every two years. Thus, prices changes would react to old information, as Klenow and Willis (2007) find using microeconomic data. Overall, sticky information anticipates that prices adjust to new macro innovations in 2.5 year. For wages, this measure corresponds to 3 years, on the average. Additionally, sticky informa- 
tion is better at approximating the dynamics of inflation measures than the backward-looking model, as measured by the SVAR, whenever enough interest rate inertia is allowed. However, when it comes to output, habit persistence proves to be a more powerful tool than applying information stickiness in households.

Adding sticky information to a standard sticky-price model may be the natural replacement for lagging inflation indexation. Yet, it seems that much more work has to be done in order to deliver a sticky information model as robust as the backward-looking model. Also, more studies about the length of updating information using micro data, as the one by Carroll (2003) or Klenow and Bils (2007), might prove useful for our understanding of information diffusion. Finally, it is important to highlight the major limitations of the present analysis. One concerns small sample biases, and other the disadvantages of limited information estimation techniques. Minimum distance estimations, as those performed herein, can suffer from both problems. ${ }^{16}$ In order to study these issues, one can use bootstrapping methods to know the effect of small sample biases on main conclusions. Also, using Bayesian estimation or maximum likelihood could verify in which dimensions the estimations presented herein are robust. We leave these issues as subjects for future research.

\footnotetext{
${ }^{16}$ See Canova and Sala (2007) for more critics of this method.
} 


\section{REFERENCES}

Andrés, J., López-Salido, J.D., and Nelson, E., 2005. Sticky Price Models and the Natural Rate of Hypothesis. Journal of Monetary Economics, $52,1025 \hat{u} 1053$.

Altig, D., Christiano, L.J., Eichenbaum, M., Linde, J., 2005. Firm-specific capital, nominal rigidities, and the business cycle. NBER working paper 11034 .

Amato, J.D., Laubach, T., 2003. Estimation and control of an optimizationbased model with sticky prices and wages. Journal of Economic Dynamics and Control, 27, 1181-1215.

Bils, M., Klenow, P.J., 2004. Some evidence on the importance of sticky prices. Journal of Political Economy, 112, 947-985.

Boivin, J., Giannoni, M.P., 2006. Has monetary policy become more effective? Review of Economics and Statistics, 88, 430-450.

Bruchez, P.A., 2007. A hybrid sticky-price and sticky information model. Manuscript.

Canova, F. and Sala, L., 2007. Back to square one: identification issues in DSGE models. Banco de España Working Papers 0715, Banco de España.

Carrillo, J. A., Matheron, J., Fève, P., 2007. Monetary policy inertia or persistent shocks: A DSGE Analysis. International Journal of Central Banking, 3, 1-38.

Carroll, C. D., 2003. Macroeconomic Expectations of Households and Professional Forecasters. Quarterly Journal of Economics, 118, 269-298.

Christiano, L.J., Eichenbaum, M., Evans, C.L., 1996. The effects of monetary policy shocks: Evidence form the flow of funds. Review of Economics and Statistics, 78, 16-34.

Christiano, L.J., Eichenbaum, M., Evans, C.L., 1999. Monetary policy shocks: What have we learned and to what end? In: Taylor, J.B., Woodford, M. (Eds.), Handbook of Macroeconomics, Vol. 1A. Elsevier, Amsterdam, 65-148. 
Christiano, L.J., Eichenbaum, M., Evans, C.L., 2005. Nominal rigidities and the dynamic effects of a shock to monetary policy. Journal of Political Economy, 113, 1-45.

Coibion, O., 2007. Testing the sticky information Phillips curve. College of William and Mary, Working paper 61.

Dupor, B., Kitamura, T., Tsuruga, T., 2008. Integrating sticky prices and sticky information. Review of Economics and Statistics, forthcoming.

Eichenbaum, M., 1992. Comment on "Interpreting the macroeconomic timeseries facts: the effects of monetary policy". European Economic Review, 36, 1001-1011.

Galí , J., Gertler, M., 1999. Inflation Dynamics: A Structural Econometric Analysis. Journal of Monetary Economics, 44, 195-222.

Giannoni, M.P., Woodford, M., 2004. Optimal inflation targeting rules. In: Bernanke, B.S. and Woodford, M., (Eds.), The Inflation Targeting Debate. University of Chicago Press, Chicago, 93-162.

Kahn, H., Zhu, Z., 2006. Estimates of the sticky information Phillips Curve for the United States. Journal of Money, Credit and Banking, 38, 195208.

Kiley, M., 2007. Quantitative Comparison of Sticky-Price and sticky information Models of Price Setting. Journal of Money, Credit and Banking, 39, 101-125.

Klenow, P. and J. Willis., 2007. Sticky Information and Sticky Prices. Journal of Monetary Economics, 54, 79-99.

Korenok, O., 2008. Empirical comparison of sticky price and sticky information models. Journal of Macroeconomics, 30, 906-927

Mankiw, G., Reis, R., 2002. Sticky Information versus Sticky Prices: a Proposal to Replace the New Keynesian Phillips Curve. Quarterly Journal of Economics, 117, 1295-1328.

Mankiw, G., Reis, R., 2007. Sticky Information in General Equilibrium. Journal of the European Economic Association, 5, 603-613.

Mojon, B., Peersman, G., 2003. A VAR description of the effects of monetary policy in the individual countries of the Euro Area. In: Angeloni, I., Kashyat, A., Mojon, B. (Eds.), Monetary policy transmission in the Euro Area, Cambridge University Press, Cambridge. 
Rotemberg, J.J., Woodford, M., 1995. Dynamic general equilibrium models with imperfectly competitive product markets. In: Cooley, T. F. (Ed.), Frontiers of Business Cycle Research, chapter 9, pages 243-293. Princeton University Press, Princeton.

Rotemberg, J.J., Woodford, M., 1997. An optimization-based econometric framework for the evaluation of monetary policy. In: Bernanke, B.S., Rotemberg, J.J. (Eds.), NBER Macroeconomics Annual. MIT Press, Cambridge, 297-346.

Rotemberg, J.J., Woodford, M., 1999. Interest-rate rules in an estimated sticky price model. In: Taylor, J.B. (Ed.), Monetary Policy Rules. University of Chicago Press, Chicago, 57-119.

Rudebusch, G.D., 2006. Monetary policy inertia: Fact or fiction? International Journal of Central Banking, 2, 85-135.

Sims, C.A., 1992. Interpreting the macroeconomic time series facts: the effects of monetary policy. European Economic Review, 36, 975-1000.

Smets, F., Wouters, R., 2007. Shocks and frictions in U.S. business cycles: A Bayesian DSGE approach. American Economic Review, 97, 586-606.

Sousa, J., Zaghini, A., 2004. Monetary policy shocks in the Euro Area and global liquidity spillovers. European Central Bank. Working Paper 309.

Taylor, J.B., 1993. Discretion versus policy rules in practice. CarnegieRochester Conference Series on Public Policy, 39, 195-214.

Trabandt, M., 2007. Sticky Information vs. Sticky Prices: A Horse Race In A DSGE Framework. Sveriges Riksbank Working Paper Series 209.

Woodford, M., 2003. Interest and Prices: Foundation of a Theory of Monetary Policy. Princeton University Press, Princeton. 

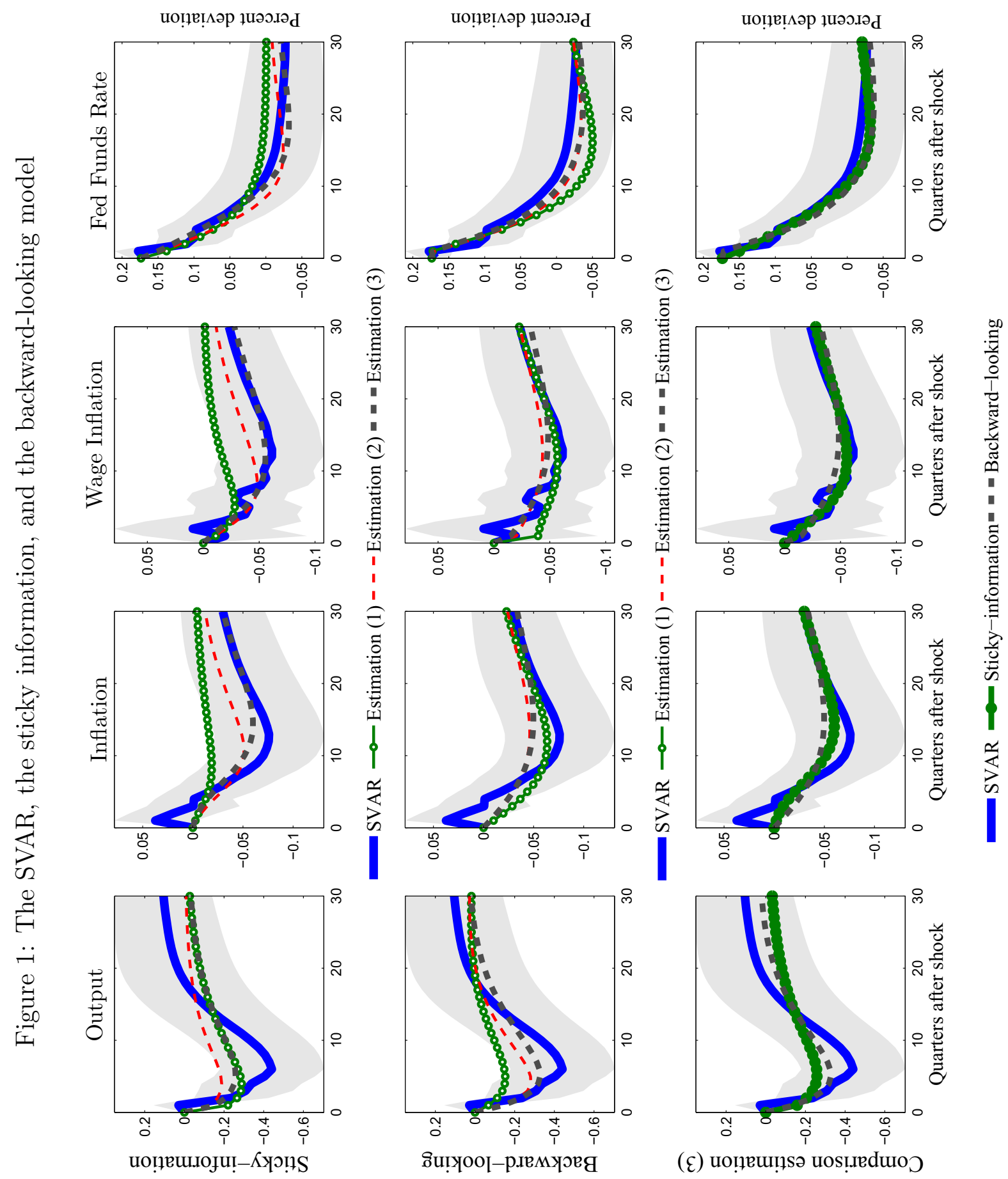

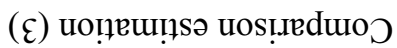


Figure 2: Substitution between price and information stickiness
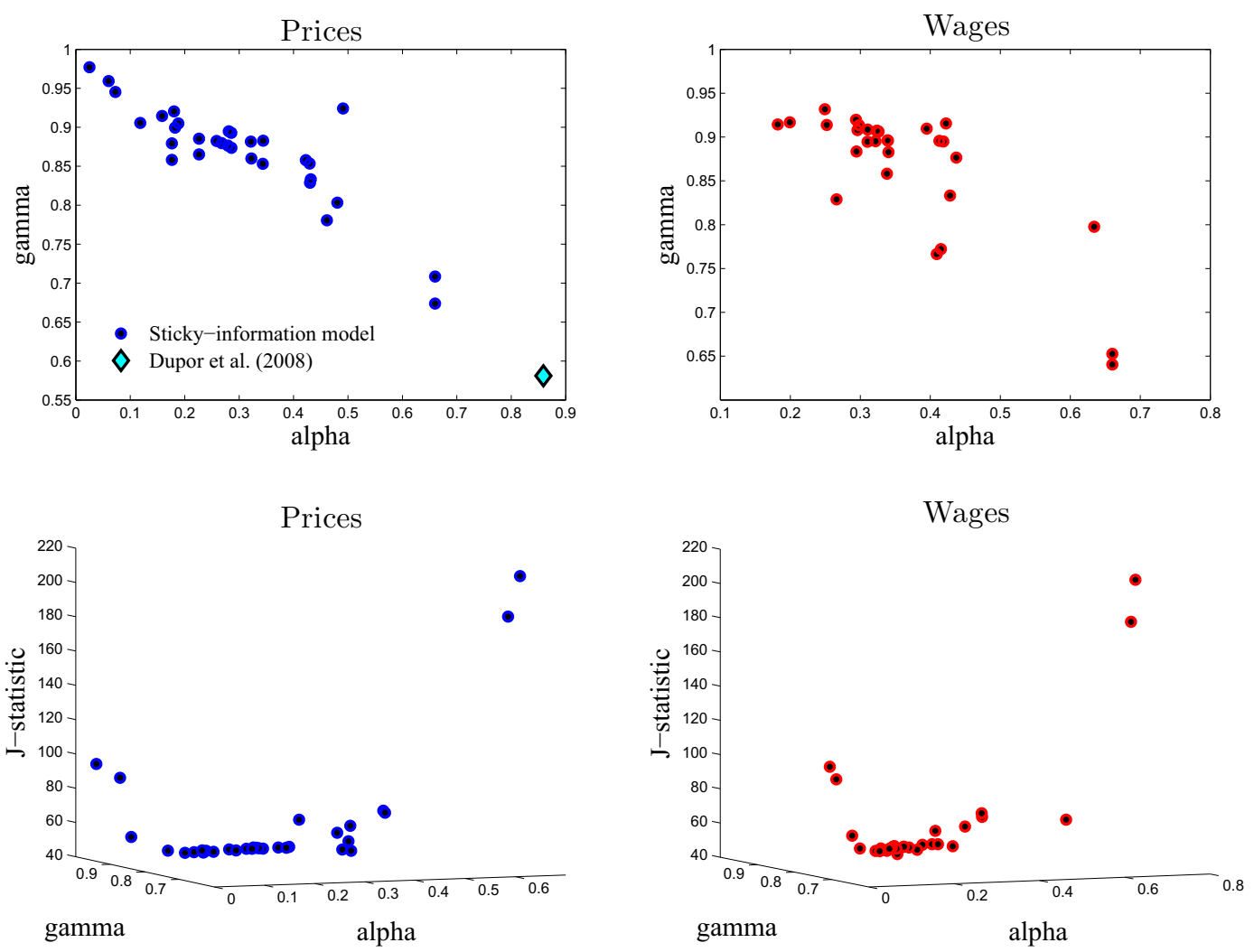
Table 1. Calibrated Parameters

\begin{tabular}{llc}
\hline Parameters & Interpretation & Value \\
\hline $\begin{array}{ll}\text { Preferences } \\
\beta\end{array}$ & Subjective discount factor & 0.99 \\
$\sigma$ & Intertemporal elasticity of substitution & 1.00 \\
$\omega_{w}$ & Elasticity of marginal labor disutility & 1.00 \\
Technology & & \\
$\phi$ & Inverse of the elasticity of $\hat{y}_{t}$ wrt $\hat{n}_{t}$ & 1.33 \\
$\omega_{p}$ & $\phi-1$ & 0.33 \\
$s_{x}$ & Share of material goods & 0.50 \\
$\theta_{p}$ & Elasticity of demand for goods & 6.00 \\
$\theta_{w}$ & Elasticity of demand for labor & 21.00 \\
Price/Wage Setting & & \\
$\alpha_{p}$ & Prob. of no price adj. & 0.66 \\
$\alpha_{w}$ & Prob. of no wage adj. & 0.66 \\
Nominal Interest Rate & Target Level \\
$a_{\pi}$ & Monetary policy reaction to $\hat{\pi}_{t}$ & \\
$a_{y}$ & Monetary policy reaction to $\hat{y}_{t}$ & 1.500 \\
$\rho_{1}$ & Policy inertia parameter & 0.125 \\
$\rho_{2}$ & Correlated shocks of the monetary shock & 0.20 \\
$\sigma_{\nu}$ & Standard deviation of the monetary innovation & 0.1736 \\
\hline
\end{tabular}


Table 2. Estimation Results

\begin{tabular}{|c|c|c|c|c|c|c|}
\hline \multirow[t]{2}{*}{ Parameter } & \multicolumn{3}{|c|}{ sticky information, $j=s i$} & \multicolumn{3}{|c|}{ Backward-looking, $j=b$} \\
\hline & (1) & $(2)$ & (3) & (1) & $(2)$ & $(3)$ \\
\hline$\gamma_{c, j}$ & $\begin{array}{l}0.9317 \\
(0.026)\end{array}$ & $\begin{array}{c}0.9618 \\
(0.021)\end{array}$ & $\begin{array}{c}0.9689 \\
(0.016)\end{array}$ & $\begin{array}{c}0.8600 \\
(0.003)\end{array}$ & $\begin{array}{c}0.7838 \\
(0.011)\end{array}$ & $\begin{array}{c}0.8078 \\
(0.131)\end{array}$ \\
\hline$\gamma_{p, j}$ & $\begin{array}{c}0.7084 \\
(0.048)\end{array}$ & $\begin{array}{c}0.9594 \\
(0.021)\end{array}$ & $\begin{array}{c}0.8929 \\
(0.158)\end{array}$ & $\begin{array}{c}1.0000 \\
(0.018)\end{array}$ & $\begin{array}{l}1.0000 \\
(0.0 .077)\end{array}$ & $\begin{array}{c}0.9853 \\
(0.117)\end{array}$ \\
\hline$\gamma_{w, j}$ & $\begin{array}{c}0.6526 \\
(0.034)\end{array}$ & $\begin{array}{c}0.9168 \\
(0.025)\end{array}$ & $\begin{array}{c}0.9067 \\
(0.049)\end{array}$ & $\begin{array}{c}1.0000 \\
(0.013)\end{array}$ & $\begin{array}{c}1.0000 \\
(0.090)\end{array}$ & $\begin{array}{c}1.0000 \\
(0.147)\end{array}$ \\
\hline$\alpha_{p, j}$ & - & $\begin{array}{c}0.0603 \\
(0.011)\end{array}$ & $\begin{array}{c}0.2857 \\
(0.057)\end{array}$ & - & $\begin{array}{c}0.7250 \\
(0.040)\end{array}$ & $\begin{array}{c}0.7574 \\
(0.224)\end{array}$ \\
\hline$\alpha_{w, j}$ & - & $\begin{array}{c}0.1993 \\
(0.037)\end{array}$ & $\begin{array}{c}0.3246 \\
(0.121)\end{array}$ & - & $\begin{array}{c}0.7820 \\
(0.044)\end{array}$ & $\begin{array}{c}0.8379 \\
(0.060)\end{array}$ \\
\hline$\rho_{e}$ & - & - & $\begin{array}{c}0.9297 \\
(0.019)\end{array}$ & - & - & $\begin{array}{c}0.9184 \\
(0.031)\end{array}$ \\
\hline $\mathcal{J}$ & $\begin{array}{c}186.41 \\
{[0.01]}\end{array}$ & $\begin{array}{l}87.27 \\
{[98.71]}\end{array}$ & $\begin{array}{l}47.13 \\
{[99.99]}\end{array}$ & $\begin{array}{l}85.26 \\
{[99.43]}\end{array}$ & $\begin{array}{l}55.66 \\
{[99.99]}\end{array}$ & $\begin{array}{l}45.06 \\
{[99.99]}\end{array}$ \\
\hline $\mathcal{J}_{y}$ & 34.14 & 37.77 & 29.70 & 38.59 & 20.29 & 15.60 \\
\hline $\mathcal{J}_{\pi}$ & 72.37 & 23.57 & 8.74 & 17.25 & 19.88 & 16.36 \\
\hline $\mathcal{J}_{\pi^{w}}$ & 60.73 & 13.00 & 2.23 & 4.86 & 5.96 & 4.62 \\
\hline $\mathcal{J}_{i}$ & 19.16 & 12.93 & 6.46 & 24.55 & 9.53 & 8.48 \\
\hline
\end{tabular}

Note : Standard deviations are stated in parenthesis, whereas the p-values are closed by brackets. The latter were calculated under the null hypothesis that $\mathcal{J}_{T}=0$, i.e., the model is able to mimic the empirical responses of the SVAR, and under the assumption that $\mathcal{J}_{T} \sim$ $\chi^{2}\left(\operatorname{dim}(\theta)-\operatorname{dim}\left(\psi_{2}\right)\right)$. 


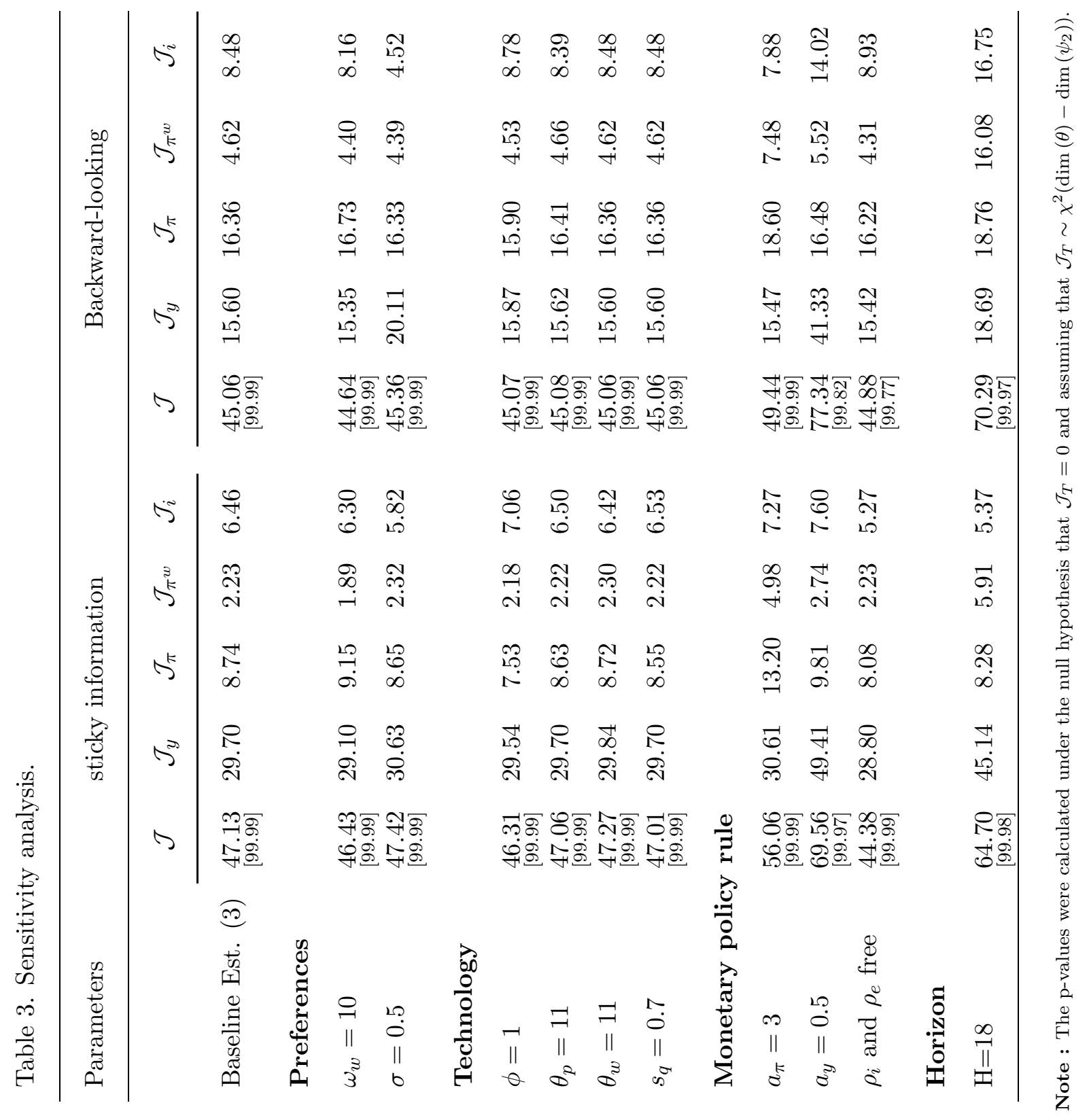




\section{APPENDIX}

\section{A The model}

Hereby, the general description of the model is presented. It is worth notice that the baseline model share the same timing restrictions than the SVAR described in Section 3. This is achieved by assuming that output, inflation, and wage inflation are decided prior to the observation of the monetary policy shock, as assumed in Rotemberg and Woodford $(1997,1999)$ and may others.

\section{A.1 Final and Material Goods}

Aggregate demand for gross output is composed of final good demand $\left(y_{t}\right)$ and material good demand $\left(q_{t}\right)$. The overall aggregate demand is $d_{t} \equiv y_{t}+$ $q_{t}$, and $P_{t}$ is the associated nominal price. Following Kimball (1995) and Woodford (2003), the production function is of the form

$$
\int_{0}^{1} G\left(\frac{d_{t}(\varsigma)}{d_{t}}\right) \mathrm{d} \varsigma=1
$$

where $d_{t}(\varsigma)$ denotes the overall demand addressed to the producer of intermediate good $\varsigma \in[0,1]$, and the function $G$ is increasing, strictly concave, and satisfies the normalization $G(1)=1$. Monopolistic firms produce the intermediate goods $\varsigma \in[0,1]$. Following Rotemberg and Woodford (1995), we assume that monopolist $\varsigma$ faces the following production possibilities

$$
\min \left\{\frac{F\left(n_{t}(\varsigma)\right)}{1-s_{q}}, \frac{q_{t}(\varsigma)}{s_{q}}\right\} \geq d_{t}(\varsigma),
$$

where $F(\cdot)$ is an increasing and concave production function, $n_{t}(\varsigma)$ denotes the input of aggregate labor (to be defined later), $q_{t}(\varsigma)$ denotes the input of material goods, and $s_{q}$ is the share of material goods in gross output. Let $\theta_{p}(z)$ denote the elasticity of demand for a producer of intermediate good facing the relative demand $z=d_{t}(\varsigma) / d_{t}$. According to our specification, $\theta_{p}(z) \equiv-G^{\prime}(z) /\left(z G^{\prime \prime}(z)\right)$. This illustrates that intermediate good firms face a varying elasticity of demand for their output, implying a varying mark-up, which is denoted by $\mu(z) \equiv \theta_{p}(z) /\left(\theta_{p}(z)-1\right)$. This turns out to be a powerful source of strategic complementarity between price setters, as shown in Woodford (2003).

Let $P_{T, l}(\varsigma)$ denote the price chosen in period $T$ by monopolist $\varsigma$, whose latest information set corresponds to $I_{t-l}$ for $l=1,2,3, \ldots$ Following Calvo (1983), 
we assume that in each period of time and prior to observing the monetary policy shock, a monopolistic firm can re-optimize its price with probability $1-\alpha_{p}$, irrespective of the elapsed time since it last revised its price. If the firm cannot re-optimize its price, the latter is rescaled according to the simple revision rule $P_{T, l}(\varsigma)=\left(1+\delta_{t, T}^{p}\right) P_{t}(\varsigma)$, where

$$
1+\delta_{t, T}^{p}=\left\{\begin{array}{ll}
\prod_{j=t}^{T-1}(1+\pi)^{1-\gamma_{p, b}}\left(1+\prod_{j}\right)^{\gamma_{p, b}} & \text { if } T>t \\
1 & \text { otherwise }
\end{array},\right.
$$

where $\Pi_{t}=P_{t} / P_{t-1}-1$ represents the inflation rate and $\pi$ is the steady state inflation rate and $\gamma_{p, b} \in[0,1]$ measures the degree of indexation to the most recently available inflation measure. We also assume that every single monopolist producer at period $t$ may, with probability $1-\gamma_{p, s i}$, reset its information set to the latest available in the economy. If it is not the case, the firm keeps its old information set.

Let $P_{l, t}^{\star}(\varsigma)$ denote the price chosen in period $t$ by monopolist $\varsigma$ if he is drawn to reoptimize. Denote $d_{t, T}^{\star}(\varsigma)$ the production of good $\varsigma$ in period $T$ if firm $\varsigma$ last reoptimized its price in period $t$. Then, $P_{t, l}^{\star}(\varsigma)$ can be defined as

$$
P_{l, t}^{\star}(\varsigma) \in \underset{P_{l, t}(\varsigma)}{\operatorname{argmax}} \mathrm{E}_{t-l} \sum_{T=t}^{\infty}\left(\beta \alpha_{p}\right)^{T-t} \lambda_{T}\left\{\frac{\left(1+\delta_{t, T}^{p}\right) P_{t, l}(\varsigma)}{P_{T}} d_{t, T}^{\star}(\varsigma)-S\left(d_{t, T}^{\star}(\varsigma)\right)\right\}
$$

s.t.

$$
\begin{aligned}
d_{t, T}^{\star}(\varsigma) & =d_{T}\left(G^{\prime}\right)^{-1}\left(\frac{\left(1+\delta_{t, T}^{p}\right) P_{t, l}^{\star}(\varsigma)}{P_{T}} \int_{0}^{1} \frac{d_{t}(u)}{d_{t}} G^{\prime}\left(\frac{d_{t}(u)}{d_{t}}\right) \mathrm{d} u\right), \text { and } \\
S\left(d_{t}(\varsigma)\right) & =W_{t} F^{-1}\left(\left(1-s_{q}\right) d_{t}(\varsigma)\right)+s_{q} d_{t}(\varsigma)
\end{aligned}
$$

for $l=1,2,3 \ldots$ where $\lambda_{t}$ is the representative household's marginal utility of wealth, $\mathrm{E}_{t-l}$ is the expectation operator conditional on the available information in time $t-l, d_{t, T}^{\star}(\varsigma)$ is the demand of good $\varsigma$, and $S\left(d_{t}(\varsigma)\right)$ is the real cost of producing $d_{t}(\varsigma)$ units of good $\varsigma$. Standard manipulations yield the approximate log-linearized price setting and inflation equations

$$
\hat{p}_{l, t}=E_{t-l}\left[\left(1-\beta \alpha_{p i}\right) \kappa_{p}\left(\omega_{p} \hat{Y}_{t}+\hat{W}_{t}\right)+\beta \alpha_{p i}\left(\hat{p}_{l, t+1}+\hat{\Pi}_{t+1}-\gamma_{p, b} \hat{\Pi}_{t}\right)\right]
$$


for $l=1,2,3, \ldots$, and

$$
\frac{\alpha_{p}}{1-\alpha_{p}}\left(\hat{\Pi}_{t}-\gamma_{p, b} \hat{\Pi}_{t-1}\right)=\left(1-\gamma_{p, s i}\right) \sum_{l=0}^{\infty} \gamma_{p, s i}^{l} \hat{p}_{l, t}
$$

with

$$
\tilde{\kappa}_{p} \equiv \frac{1}{\left(1-\mu s_{q}\right)^{-1}\left(1+\theta_{p} \epsilon_{\mu}\right)+\theta_{p} \omega_{p}} .
$$

The above equations are expressed in terms of the log-deviations from the steady state levels. $\theta_{p} \equiv \theta_{p}(1)$ is the steady state elasticity of demand for a producer of intermediate good, and $\omega_{p}$ is the real marginal cost elasticity with respect to the level of production, equal to

$$
\omega_{p} \equiv-\frac{F^{\prime \prime}(n) n}{F^{\prime}(n)} \frac{F(n)}{F^{\prime}(n) n} .
$$

$F(n), F^{\prime}(n)$, and $F^{\prime \prime}(n)$ denote the value of $F$ and its first and second derivatives, evaluated at the steady state value of $n$. Following Woodford (2003), we let $\epsilon_{\mu}$ denote the elasticity of $\mu(\xi)$ in the neighborhood of $\xi=1$, i.e. $\epsilon_{\mu}=\mu^{\prime}(1) / \mu(1)$. Equation (2) comes from the assumption that $\gamma_{p, b}=0$ while $\gamma_{p, s i}>0$. For equation (13), it is assumed that $\gamma_{p, b}>0$ while $\gamma_{p, s i}=0$.

\section{A.2 Aggregate labor index and Households}

Following Erceg et al. (2000), we assume for convenience that a set of differentiated labor inputs, indexed by $v \in[0,1]$, are aggregated into a single labor index $h_{t}$ by competitive firms, which will be referred hereafter as labor intermediaries. The latter produce the aggregate labor input according to the following Constant Elasticity of Substitution technology

$$
h_{t}=\left(\int_{0}^{1} h_{t}(v)^{\left(\theta_{w}-1\right) / \theta_{w}} \mathrm{~d} v\right)^{\theta_{w} /\left(\theta_{w}-1\right)},
$$

where $\theta_{w}>1$ is the elasticity of substitution between any two labor types. The associated aggregate nominal wage obeys

$$
W_{t}=\left(\int_{0}^{1} W_{t}(v)^{1-\theta_{w}} \mathrm{~d} v\right)^{1 /\left(1-\theta_{w}\right)},
$$

where $W_{t}(v)$ denotes the nominal wage rate associated to type- $v$ labor. 
The economy is inhabited by a continuum of differentiated households, indexed by $v \in[0,1]$. A typical household selects a sequence of consumptions and nominal money and bond holdings, as well as a nominal wage. Households differ in two dimensions: first, by the information they have available at the time they take their decisions; and second, by the specific labor type they are endowed with. Household v's objective is to maximize

$$
\mathrm{E}_{\Phi_{t}} \sum_{T=t}^{\infty} \beta^{T-t}\left[U\left(c_{T}-\gamma_{c, b} c_{T-1}, m_{T}\right)-V\left(h_{T}(v)\right)\right],
$$

subject to the sequence of constraints

$$
P_{t} c_{t}+M_{t}+\frac{B_{t}}{1+i_{t}} \leq W_{t}(v) h_{t}(v)+B_{t-1}+M_{t-1}+\Upsilon_{t}+P_{t} \operatorname{div}_{t}
$$

where $\mathrm{E}_{\Phi_{t}}$ is a conditional expectation operator reflecting the particular information set at the household's disposal when taking their decisions. Namely, it is assumed that consumption and wages are decided prior the realization of shocks, while bonds and money holdings are decided afterwards. $\beta \in(0,1)$ is the subjective discount factor, $\gamma_{c, b} \in[0,1)$ is the habit parameter, $c_{t}$ is consumption, $m_{t}=M_{t} / P_{t}$ denotes real cash balances at the end of the period, where $M_{t}$ denotes nominal cash balances; $h_{t}(v)$ denotes household $v$ 's labor supply at period $t$; $\operatorname{div}_{t}$ denotes real profits redistributed by monopolistic firms; $B_{t}$ denotes the nominal bonds acquired in period $t$ and maturing in period $t+1 ; i_{t}$ denotes the gross nominal interest rate; $\Upsilon_{t}$ is a nominal transfer from the government. As in Woodford (2003), we assume that there is a satiation level $m^{*}$ for real balances such that $U_{m}=0$ for $m \geq m^{*}$. Thus, when $m_{t}$ reaches $m^{*}$ from below, the transaction services of real cash balances yield lower and lower marginal utility. We also consider, for the sake of simplicity, a separable utility function between money and consumption.

Households are composed of two entities: a consumer and a worker. The former chooses consumption, money, and bond holdings, while the latter sets his wage by using his monopolistic power, since every household is different, depending on its labor type. As Mankiw and Reis (2007), we allow consumers to have a different frequency of processing new information than workers, as this will give a different dimensions to consumption and wage inflation inertia. The latter implies that the probabilities of updating (and processing) new information is different: let $1-\gamma_{c, b}$ denote this probability for the consumer and $1-\gamma_{w, b}$ for the worker. 


\section{A.2.1 The consumer decision}

Let $\lambda_{t}$ denote the Lagrange multiplier associated with the household's budget constraint. The loglinearization of the first order conditions associated with $c_{t}, B_{t}$, and $M_{t}$ for a consumer with information set $I_{t-l}$ yields

$$
\begin{gathered}
\mathrm{E}_{t-l-k}\left[\beta \gamma_{c, b}\left(\hat{c}_{l, t+1}-\gamma_{c, b} \hat{c}_{l, t}\right)\right]=\mathrm{E}_{t-l-k}\left[\hat{c}_{l, t}-\gamma_{c, b} \hat{c}_{l, t-1}+\varphi^{-1} \hat{\lambda}_{l, t}\right], \\
\hat{\lambda}_{l, t}=\mathrm{E}_{t-l}\left[\hat{\imath}_{t}+\hat{\lambda}_{l, t+1}-\hat{\Pi}_{t+1}\right] . \\
\hat{m}_{l, t}=\mathrm{E}_{t-l-k}\left[\eta_{y} \lambda_{l, t}-\eta_{i} \hat{\imath}_{t}\right] .
\end{gathered}
$$

for $l=0,1,2,3, \ldots$, with

$$
k= \begin{cases}0, & \text { if } l>0 \\ 1, & \text { if } l=0\end{cases}
$$

Aggregate consumption and money demand are given by:

$$
\begin{aligned}
& \hat{C}_{t}=\left(1-\gamma_{c, s i}\right) \sum_{l=0}^{\infty} \gamma_{c, s i}^{l} \hat{c}_{l, t} \\
& \hat{m}_{t}=\left(1-\gamma_{c, s i}\right) \sum_{l=0}^{\infty} \gamma_{c, s i}^{l} \hat{m}_{l, t}
\end{aligned}
$$

where $\hat{c}_{l, t}, \hat{m}_{l, t}, \hat{\imath}_{t}$, and $\hat{\lambda}_{l, t}$ are the log-deviations of $c_{l, t}, m_{l, t}, 1+i_{t}$, and $\lambda_{l, t}$, respectively, and the auxiliary parameters $\sigma, \varphi, \eta_{y}$, and $\eta_{i}$ are defined as

$$
\begin{gathered}
\sigma^{-1}=-\frac{U_{c c} c}{U_{c}}, \quad \varphi^{-1}=\left(1-\beta \gamma_{c, b}\right) \sigma, \\
\eta_{y}=\eta_{i} \frac{\bar{\imath}}{1+\bar{\imath}}, \quad \eta_{i}=-\frac{\left(1-\beta \gamma_{c, b}\right) U_{c}}{U_{m m} m} .
\end{gathered}
$$

$\bar{\imath}$ is the steady state value of the nominal interest rate. Equation (A-3) illustrates the role played by habits in consumption, which reinforces the backward dimension of the IS curve. Equation (A-4) is the standard Euler equation on bond holdings. Finally, equation (A-5) is a standard money demand function. Equation (1) comes from the assumption that $\gamma_{c, b}=0$ while $\gamma_{c, s i}>0$. For equation (11), it is assumed that $\gamma_{c, b}>0$ while $\gamma_{c, s i}=0$. 


\section{A.2.2 The worker decision}

A typical household $v$ acts as a monopoly supplier of type- $v$ labor. It is assumed that at each point in time only a fraction $1-\alpha_{w}$ of the households can set a new wage, which will remain fixed until the next time period the household is drawn to reset its wage. The remaining households simply revise their wages according to the backward-looking rule $W_{T}(v)=\left(1+\delta_{t, T}^{w}\right) W_{t}(v)$, where

$$
1+\delta_{t, T}^{w}=\left\{\begin{array}{ll}
\prod_{j=t}^{T-1}(1+\pi)^{1-\gamma_{w, b}}\left(1+\Pi_{j}\right)^{\gamma_{w, b}} & \text { if } T>t \\
1 & \text { otherwise }
\end{array},\right.
$$

where $\gamma_{w, b} \in[0,1]$ measures the degree of indexation to the most recently available inflation measure.

The implied labor-type $v$ demand by the labor intermediaries is

$$
h_{T}(v)=\left(\frac{\left(1+\delta_{t, T}^{w}\right) W_{t}(v)}{W_{T}}\right)^{-\theta_{w}} h_{T} .
$$

$W_{t}(v)$ is then selected so as to maximize

$$
\mathrm{E}_{t-l} \sum_{T=t}^{\infty}\left(\beta \alpha_{w}\right)^{T-t}\left\{\lambda_{T} \frac{\left(1+\delta_{t, T}^{w}\right) W_{t}(v)}{P_{T}} h_{t}(v)-V\left(h_{t}(v)\right)\right\} .
$$

for $l=1,2,3, \ldots$, subject to the specific labor demand just described above. Log-linearizing the associated first order condition yields

$$
\hat{w}_{l, t}=E_{t-l}\left[\left(1-\beta \alpha_{w}\right) \tilde{\kappa}_{w}\left(\omega_{w} \phi \hat{c}_{t}-\hat{\lambda}_{t}-\hat{W}_{t}\right)+\beta \alpha_{w}\left(\hat{w}_{l, t+1}+\hat{\Pi}_{t+1}^{w}-\gamma_{w, b} \hat{\Pi}_{t}\right)\right]
$$

and

$$
\frac{\alpha_{w}}{1-\alpha_{w}}\left(\hat{\Pi}_{t}^{w}-\gamma_{w, b} \hat{\Pi}_{t-1}\right)=\left(1-\gamma_{w, s i}\right) \sum_{l=0}^{\infty} \gamma_{w, s i}^{l} \hat{w}_{l, t}
$$

where $\hat{\Pi}_{t}^{w}$ is wage inflation, and the auxiliary parameters $\phi, \tilde{\kappa}_{\omega}$, and $\omega_{\omega}$ are defined as

$$
\phi=\frac{F(n)}{F^{\prime}(n) n}, \quad \tilde{\kappa}_{w}=\frac{1}{1+\omega_{w} \theta_{w}}, \quad \omega_{w}=\frac{V_{h h} h}{V_{h}} .
$$

Here, $\gamma_{w, b}$ governs the sensitivity of nominal wages to lagged inflation, and thus reinforces the persistence of wage inflation. In contrast, $\gamma_{w, s i}$ is equivalent to the proportion of workers that are unaware about the shocks in monetary policy in period $t$. Equation (3) comes from the assumption that $\gamma_{w, b}=0$ while $\gamma_{w, s i}>0$. For equation (14), it is assumed that $\gamma_{w, b}>0$ while 
$\gamma_{w, s i}=0$. Finally, notice that $\hat{\Pi}_{t}$ and $\hat{\Pi}_{t}^{w}$ are linked together through the relation

$$
\hat{\Pi}_{t}^{w}=\hat{W}_{t}-\hat{W}_{t-1}+\hat{\Pi}_{t}
$$

which is a simple "accounting" identity.

\section{A.3 Monetary Policy}

The model is closed by postulating a monetary policy rule of the form

$$
\begin{gathered}
\hat{\imath}_{t}^{*}=a_{\pi} \hat{\pi}_{t}+a_{y} \hat{y}_{t}, \\
\hat{\imath}_{t}=\rho_{1} \hat{\imath}_{t-1}+\left(1-\rho_{1}\right) \hat{\imath}_{t}^{*}+e_{t}, \\
e_{t}=\rho_{2} e_{t-1}+\nu_{t}, \quad \nu_{t} \sim \operatorname{iid}\left(0, \sigma_{\nu}^{2}\right) .
\end{gathered}
$$

Equation (A-11) is similar to that proposed by Taylor (1993). Here $\hat{\imath}_{t}^{*}$ is the target interest rate that depends on current inflation and (model-based) output gaps. More precisely, $a_{\pi}$ and $a_{y}$ govern the sensitivity of the desired level of the nominal interest rate to the log deviations of inflation and output gaps. The monetary policy rule delivers interest rate persistence from two sources. First, the central bank's aim in smoothing the interest rate is denoted by $\rho_{i}$; and second, persistent deviations from the baseline rule, which consists of the discretionary part of monetary policy, are denoted by $\rho_{e}$.

\section{A.4 Equilibrium}

In equilibrium, it must be the case that $Y_{t}=C_{t}$ and $h_{t}=n_{t}$. Furthermore, from the aggregate production function, it must also be the case that $\hat{n}_{t}=\phi \hat{Y}_{t}$, where $\phi^{-1}=F^{\prime}(n) n / F(n)$. Substituting these relations in the system composed of (A-1)-(A-13), we obtain a rational expectations system of linear equations.

In the case of the backward-looking model, i.e. when $\gamma_{x, b}>0$ and $\gamma_{x, s i}=0$ for $x \in\{p, c, w\}$, the rational expectations system (11)-(15) is solved using standard methods. For the case of the extended sticky information model, i.e. when $\gamma_{x, s i}>0$ and $\gamma_{x, b}=0$, the method of resolution is a bit more complex, and is presented next. 


\section{B Resolution by undetermined coefficients}

\section{B.1 Solving a simple sticky-information model}

In order to introduce the main idea behind the resolution of a rational expectation models with information lags, please consider the following very simple and stylized model. There are only two variables in the economy: one endogenous, $c_{t}$, that is determined according to a decision rule; and one exogenous, $x_{t}$, which we consider to follow an AR(1) process. Also, assume there is a continuum of agents distributed into two types: the fully informed agent and the less aware agent. The information set of the fully aware agent correspond to the most available in the economy, where the description of shocks and the evolution of $x_{t}$ in the present period are given; this set of news is denoted by $I_{t}$. The less inform agent becomes aware of the evolution of shocks only $l^{\prime}>0$ periods after they are realized, so his information set is given by $I_{t-l^{\prime}}$. In all other respects, including preferences, both agents are just the same. This implies that both agents will act similarly whenever they share the same information.

Define $c_{l, t}$ as the decision made in period $t$ by agent with information set $I_{t-l}$, for $l \in\left\{0, l^{\prime}\right\}$. Also, define $1-\mu$ as the proportion of fully aware agents in the economy. Therefore, $C_{t}=(1-\mu) c_{0, t}+\mu c_{l^{\prime}, t}$ at each and every period. For the sake of simplicity, let the decision rule for which agent $l$ determines $c_{l, t}$ be the following (e.g., think in the euler equation of consumption, for instance, in a simple DSGE model):

$$
c_{l, t}=E_{t-l}\left(c_{l, t+1}+b x_{t}\right)
$$

where $E_{t-l}$ denotes the expectation operator conditional to the information set $I_{t-l}$ and $b$ is a constant. If $x_{t}$ follows a process like

$$
x_{t}=\rho x_{t-1}+\sigma \varepsilon_{t} \quad \text { with } \quad \varepsilon_{t} \sim i d d(0,1),
$$

where $\sigma>0$ is a constant and $\rho \in(0,1)$ measures the degree of persistence of $x_{t}$, then, the equilibrium dynamics of variable $c_{l, t}$ are given by:

$$
c_{l, t}=E_{t-l}\left(\frac{b}{1-\rho} x_{t}\right)
$$

for $l \in\left\{0, l^{\prime}\right\}$. The direct implication is that $c_{l^{\prime}, t}=E_{t-l^{\prime}} c_{0, t}$. Therefore, $c_{l^{\prime}, t}=c_{0, t}$ whenever $I_{t}=I_{t-l^{\prime}}$. This implies that we can focus on the responses of the fully aware agent, in order to disentangle the dynamics of $C_{t}$, 
the aggregate endogenous variable.

Assume we depart from the steady state equilibrium at period -1, and a shock hits the economy in period 0 (i.e., $\varepsilon_{-1}=0$ and $\varepsilon_{0} \neq 0$ ). Assume also that $l^{\prime}=1$. If no further perturbations hit the economy afterwards, the above example implies that the evolution of $C_{t}$ is given by:

$$
\begin{array}{rlrl}
C_{-1} & =0 & & \\
C_{0} & =(1-\mu) c_{0,0} & \\
C_{1} & =(1-\mu) c_{0,1}+\mu c_{1,1}=c_{0,1}, & \text { since } & c_{1,1}=c_{0,1} \\
C_{2} & =c_{0,2} & & \text { and so on }
\end{array}
$$

In the case where $1-\mu$ represents the probability of updating and processing new information by any agent in each and every period, independently of the elapsed period he last updated, we will end up in an economy with an infinite type of agents. In the latter case, a proportion $1-\mu$ of agents would have the latest information available, $(1-\mu) \mu$ would posses $I_{t-1},(1-\mu) \mu^{2}$ would have $I_{t-2}$, and so on. In the example just given above, i.e., when the economy is hit by a shock only in period 0, the dynamics of the aggregate variable at period $T>0$ will be given by:

$$
C_{T} \equiv(1-\mu) \sum_{l=0}^{\infty} \mu^{l} c_{l, T}=(1-\mu) \sum_{k=0}^{T} \mu^{k} c_{0, T}=\left(1-\mu^{T+1}\right) c_{0, T}
$$

In this special case, there is no interaction between agents, and therefore we can find a closed-form solution for the variable $c_{0, t}$. But when interactions do exist among agents, then a closed-form solution for $c_{0, t}$ is rather the exception than the rule. Consider, for example, that the exogenous variable follows the rule $x_{t}=\eta C_{t}+\varepsilon_{t}$. In this case, the decision of the agent with full information is directly influenced by the agents with lagged information. The dimension of the rational expectations model directly expands to account for all type of agents. To avoid this problem, one can use an approach based on undetermined coefficients.

\section{B.2 Undetermined coefficients}

We make now explicit reference to the system of equations (1)-(9). The aggregate dynamics at equilibrium of the model economy imply that the deviations from the steady state are history dependent on the sequence of shocks 
in monetary policy $\nu_{t}$. Thus, the price level that fully aware firms charge at time $t$ (if drawn to re-optimize) can be represented as: $\hat{p}_{0, t}=\sum_{k=0}^{\infty} p_{0 k} \nu_{t-k}$, where $p_{0 k}$ is function of the deep parameters of the economy. In the same vein, firms with one information lag set $\hat{p}_{1, t}=\sum_{k=0}^{\infty} p_{1 k} \nu_{t-k}$. In this latter case, by definition, the coefficient $p_{10}$ equals zero, since the firm is not aware about the current shock $\nu_{t}$.

Agents with the same technology or preferences will choose the same decisions when facing similar environments. In this case, agents of equal kind, sharing the same information, will choose the same things. The direct implication if this statement is that lagged information agents will mimic the fully aware agent. Thus, $p_{j k}=p_{0 k}$ whenever $j \geq k$, and 0 otherwise. Thus, we can simply focus on the fully aware agents to determine the equilibrium dynamics of the whole economy. ${ }^{17}$

Inflation would thus be determined by:

$$
\hat{\Pi}_{t}=\sum_{k=0}^{\infty} \Pi_{k} \nu_{t-k}
$$

where

$$
\begin{aligned}
\Pi_{k} & =\frac{1-\alpha_{p}}{\alpha_{p}}\left(1-\gamma_{p, s i}\right) p_{0 k} \sum_{j=0}^{k} \gamma_{p, s i}^{j} \\
& =\frac{1-\alpha_{p}}{\alpha_{p}}\left(1-\gamma_{p, s i}^{k+1}\right) p_{0 k}
\end{aligned}
$$

The same reasoning applies for output and wage inflation, whose behavior can be totally expressed in terms of the fully aware agents:

$$
\begin{gathered}
\hat{Y}_{t}=\sum_{k=0}^{\infty} Y_{k} \nu_{t-k} \\
\hat{\Pi}_{t}^{w}=\sum_{k=0}^{\infty} \Pi_{k}^{w} \nu_{t-k}
\end{gathered}
$$

\footnotetext{
${ }^{17}$ It is possible to show that lagged information agents, in this model, have no incentives to overreact or to compensate their lack of awareness. They just adjust as soon as they learn new information; this translates, by their optimality welfare-maximizing conditions, into "bygones are bygones".
} 
with

$$
\begin{aligned}
Y_{k} & =\left(1-\gamma_{c, s i}^{k+1}\right) y_{0 k} \\
\Pi_{k}^{w} & =\frac{1-\alpha_{w}}{\alpha_{w}}\left(1-\gamma_{w, s i}^{k+1}\right) w_{0 k}
\end{aligned}
$$

where $y_{0 k}$ and $w_{0 k}$ are the $k$ coefficients from the consumption and real wages sequence of the full informed agents.

Let vector $x_{k}=\left[y_{0 k}, p_{0 k}, w_{0 k}, W_{k}, i_{k}, e_{k}\right]^{\prime}$ contain the $k$ coefficients for consumption, prices, and real wages for the fully aware agents, plus aggregate real wages, nominal interest rates, and the persistent monetary shock, respectively. Equations (1)-(9) implies that we can express the undetermined coefficients $k$ as the solution of the system:

$$
A_{k} x_{k}=B_{k} x_{k+1}
$$

where $A_{k}$ and $B_{k}$ are $6 \times 6$ matrices that stands for:

$$
\begin{aligned}
& A_{k}=\left(\begin{array}{cccccc}
1 & \sigma \frac{1-\alpha_{p}}{\alpha_{p}}\left(1-\gamma_{p, s i}^{k+2}\right) & 0 & 0 & 0 & 0 \\
0 & \beta_{p} & 0 & 0 & 0 & 0 \\
0 & 0 & \beta_{w} & 0 & 0 & 0 \\
0 & -\frac{1-\alpha_{p}}{\alpha_{p}}\left(1-\gamma_{p, s i}^{k+1}\right) & \frac{1-\alpha_{w}}{\alpha_{w}}\left(1-\gamma_{w, s i}^{k+1}\right) & 1 & 0 & 0 \\
-\tilde{a}_{y} & -\tilde{a}_{p} & 0 & 0 & 1 & -1 \\
0 & 0 & 0 & 0 & 0 & 1
\end{array}\right) \\
& B_{k}=\left(\begin{array}{cccccc}
1 & 0 & 0 & 0 & 0 & 0 \\
-\left(1-\alpha_{p} \beta\right) \tilde{\kappa}_{p} \omega_{p}\left(1-\gamma_{c, s i}^{k+1}\right) & 1 & 0 & -\left(1-\alpha_{p} \beta\right) \kappa_{p} & 0 & 0 \\
-\left(1-\alpha_{w} \beta\right) \tilde{\kappa}_{\omega} \tilde{\omega}_{\omega}\left(1-\gamma_{c, s i}^{k+1}\right) & 0 & 1 & \left(1-\alpha_{w} \beta\right) \kappa_{\omega} & 0 & 0 \\
0 & 0 & 0 & 1 & 0 & 0 \\
0 & 0 & 0 & 0 & 1 & 0 \\
0 & 0 & 0 & 0 & 0 & \rho_{e}
\end{array}\right)
\end{aligned}
$$

with $\beta_{j}=\beta\left(\alpha_{j}+\left(1-\alpha_{j}\right)\left(1-\gamma_{j, h}^{k+2}\right)\right)$ for $j \in\{p, w\}, \tilde{a}_{y}=\left(1-\rho_{i}\right) a_{y}(1-$ $\left.\gamma_{c, s i}^{k+1}\right), \tilde{a}_{p}=\left(1-\rho_{i}\right) a_{p} \frac{1-\alpha_{p}}{\alpha_{p}}\left(1-\gamma_{p, s i}^{k+1}\right)$, and $\tilde{\omega}_{\omega}=\omega_{\omega} \phi+\sigma^{-1}$. The essential characteristic of this system is that matrices $A_{k}$ and $B_{k}$ depend upon the ordering of the undetermined coefficients. If there were no informational lags (all $\gamma$ 's equal zero), $A$ and $B$ will be constant, and thus by knowing the first series of coefficients $(\mathrm{k}=0)$ we would know the rest of them trough a 
geometrical decreasing sequence. The fact that more and more agents are adjusting every period, makes the algorithm non-linear, yielding a persistent path for $x_{k}$. In such a case, we have to solve for $x_{k}, x_{k+1}, x_{k+2}$, and so on, since aggregate variables are changing all the time, adding the reactions of the agents who become aware.

Define $z_{k}=Q_{k}^{-1} x_{k}$, where $Q_{k}^{-1}$ is the inverse of the matrix formed with the eigenvectors of $B_{k}^{-1} A_{k}$. Therefore, we can express

$$
z_{k}=\Lambda_{k} z_{k+1}
$$

where $\Lambda_{k}$ is a diagonal matrix with the eigenvalues of matrix $B_{k}^{-1} A_{k}$. Also, we need additional information concerning the initial conditions of the economy and the distribution of shocks. For the former, we assume all predetermined variables equal to zero, that is: $W_{-1}=i_{-1}=e_{-1}=0$. For the latter, the $\mathrm{AR}(1)$ process of the monetary shocks implies: $e_{k}=\rho_{e}^{k} \sigma_{\nu} \quad \forall j \geq 0$. The above system is then solved by standard methods. Notice that if we want to analyze an horizon of $T$ periods after the incidence of a monetary policy shock, we have to solve the system for $k=0,1,2, \ldots, T$, that is, $T+1$ times. This concludes the description of the resolution algorithm.

Determinacy. The determinacy of the model do not depend on the informational structure of the economy. If we want to determine whether the model presents a determinate equilibrium, we only have to check the case of full information, that is when all $\gamma_{j, h}$ are equal to zero. Thus, if the number of eigenvalues that are inside the unit circle corresponds to the number of free variables (in this case $y_{k}, p_{k}$, and $w_{k}$ ), then the system has a regular equilibrium and is not driven by sunspot shocks. 